\title{
AG01 in association with NEAT1 IncRNA contributes to nuclear and 3D chromatin architecture in human cells
}

Muhammad Shuaib ${ }^{1,5}$, Krishna Mohan Parsi ${ }^{2,5}$, Hideya Kawaji ${ }^{3}$, Manjula Thimma ${ }^{1}$, Sabir Abdu Adroub $^{1}$, Alexandre Fort ${ }^{3}$, Yanal Ghosheh ${ }^{1}$, Tomohiro Yamazaki ${ }^{4}$, Taro Mannen ${ }^{4}$, Loqmane Seridi $^{1}$, Bodor Fallatah ${ }^{1}$, Waad Albawardi ${ }^{1}$, Timothy Ravasi ${ }^{1}$, Piero Carninci ${ }^{3}$, Tetsuro Hirose ${ }^{4}$, Valerio Orlando ${ }^{1,2^{*}}$

1. King Abdullah University of Science and Technology (KAUST), BESE Division, KAUST Environmental Epigenetics Program, Thuwal, 23955-6900, Saudi Arabia

2. IRCSS Fondazione Santa Lucia, Epigenetics and Genome Reprogramming, Rome, Italy.

3. RIKEN Center for Life Science Technologies, Division of Genomic Technologies, 1-7-22 Suehiro-cho, Tsurumi-ku, Yokohama, Kanagawa 230-0045, Japan.

4. Institute for Genetic Medicine, Hokkaido University, Sapporo 060-0815, Japan

5. These authors contributed equally to this work

Key Words: Nuclear Argonaute-1, NEAT1 paraspeckles, genome organization, and gene regulation

"Correspondence should be addressed to Valerio Orlando

(valerio.orlando@kaust.edu.sa) 


\begin{abstract}
Aside from their roles in the cytoplasm, RNA-interference components have been reported to localize also in the nucleus of human cells. In particular, AGO1 associates with active chromatin and appears to influence global gene expression. However, the mechanistic aspects remain elusive. Here, we identify AGO1 as a paraspeckle component that in combination with the NEAT1 IncRNA maintains 3D genome architecture. We demonstrate that AGO1 interacts with NEAT1 IncRNA and its depletion affects NEAT1 expression and the formation of paraspeckles. By Hi-C analysis in AGO1 knockdown cells, we observed global changes in chromatin organization, including TADs configuration, and $A / B$ compartment mixing. Consistently, distinct groups of genes located within the differential interacting loci showed altered expression upon AGO1 depletion. NEAT1 knockout cells displayed similar changes in TADs and higher-order A/B compartmentalization. We propose that AGO1 in association with NEAT1 IncRNA can act as a scaffold that bridges chromatin and nuclear bodies to regulate genome organization and gene expression in human cells.
\end{abstract}




\section{Introduction}

Argonaute (AGO) proteins are key components of the RNA interference (RNAi) pathway and are mainly recognized for their role in post-transcriptional gene silencing via RNA guided mechanisms in the cytoplasm (Joshua-Tor and Hannon 2011; Meister 2013). In fission yeast Ago proteins and small RNAs are essential for heterochromatin formation (Volpe et al. 2002) and, similarly, in plants in RNA-dependent DNA methylation (Zilberman et al. 2003). However, a direct function of RNAi components in animal cell chromatin-mediated transcriptional regulation remains unclear. We previously reported that in Drosophila, RNAi components (dAgo2 and Dicer) are preferentially associated with active chromatin and affect transcription by regulating RNA Pol II pausing and stress response (Cernilogar et al. 2011). Another report indicated that in Drosophila dAgo2 associates with insulator proteins CTCF/CP190 at active promoters and controls CTCF/CP190-dependent looping interactions between insulators, promoters, and enhancers (Moshkovich et al. 2011). In human cells, AGO1 binds RNA pol II (Huang et al. 2013) to associate with active promoters (Huang et al. 2013), enhancers (Allo et al. 2014), HP1a, and CTCF (Agirre et al. 2015) and affects splicing (Ameyar-Zazoua et al. 2012; Allo et al. 2014; Agirre et al. 2015). The association of AGO1 with active enhancers was postulated to be mediated by long nuclear RNAs (Allo et al. 2014). However, the involvement of RNA(s) in AGO1 nuclear function and its direct or indirect mechanistic effects on chromatin and transcription remains unclear.

A body of evidence indicates a functional role of some long non-coding RNAs (IncRNAs) in controlling the activity of chromatin remodelers and nuclear compartmentalization (Rinn and Chang 2012). Among IncRNAs, Nuclear Enriched Assembly Transcript 1 (NEAT1) is an essential structural component of nuclear bodies called paraspeckles. The NEAT1 locus produces two isoforms of NEAT1 transcripts (3.7-kb NEAT1_1 and 23-kb NEAT1_2 in human), and its transcription is the first step in paraspeckle 
construction (Clemson et al. 2009; Mao et al. 2011). The concomitant association with $>50$ "paraspeckle associated" proteins (PSPs) produces a de novo paraspeckle (Sasaki et al. 2009; Naganuma et al. 2012; Chujo et al. 2017). Though the exact function of paraspeckles remains unclear, their dynamic assembly is believed to regulate gene expression (Prasanth et al. 2005; Hirose et al. 2014; Imamura et al. 2014). The genomewide association of NEAT1 IncRNA with active sites (West et al. 2014) and phaseseparation mediated NEAT1 dependent paraspeckles assembly (Yamazaki et al. 2018) suggest that NEAT1 paraspeckle and its associated protein factors may be required for regulating nuclear architecture and gene expression. However, a potential contribution of the NEAT1 IncRNA and paraspeckles in shaping three-dimensional chromatin organization has not yet been tested.

Recently, genome-wide chromosome conformation capture analysis ( $\mathrm{Hi}-\mathrm{C}$ ) has revealed that chromosomes are organized into active (open, A-type) and inactive (closed, B-type) compartments (Lieberman-Aiden et al. 2009), which are further composed of clusters of interactions called Topologically Associated Domains (TADs), separated by boundary regions (Dixon et al. 2012; Nora et al. 2012). The 3D chromatin structure is believed to regulate gene expression by establishing loops between enhancers and promoters, and/or by bridging regulatory elements and genes into spatial chromatin hubs, compartments, and domains (Bouwman and de Laat 2015). Several chromatin regulators, including Polycomb proteins, Cohesin, CTCF, and Mediator complex have been reported to influence 3D genome organization (Kagey et al. 2010; Delest et al. 2012; Seitan et al. 2013; Sofueva et al. 2013; Zuin et al. 2014). However, the collective role of RNA binding proteins like RNAi components and IncRNA (Yang et al. 2013) has been poorly investigated.

Here, we have applied a combination of genome-wide approaches to investigate the role of chromatin-bound AGO1 and its associated RNA in 3D genome conformation and 
gene expression. Collectively, our data unveil an unprecedented link between nuclear AGO1 and NEAT1 IncRNA, which contribute to the stability of sub-nuclear compartment and fine-tuning of higher-order chromatin architecture and gene expression in human cells.

\section{Results}

\section{AG01 depletion results in deregulation of coding and non-coding transcripts at}

\section{the genome-wide level}

Despite the previously reported association of AGO1 with active promoters and enhancers, its direct or indirect effects on transcription remain unclear. To evaluate the impact of AGO1 depletion on global transcriptional changes of all expressed TSS, we decided to use CAGE-seq analysis (Takahashi et al. 2012). We applied CAGE-seq analysis on total, and chromatin extracted RNA from control (siCtrl) and AGO1 depleted (siAGO1) cells (Supplemental Fig. S1e-i, and see supplemental results). We identified more than 1,000 genes in both total and chromatin-bound RNA CAGE-seq data that were differentially expressed (DE) (Fig. 1A-B and Supplemental Fig. S2a-b). We observed deregulation of not only coding transcripts but also a significant change in noncoding transcript levels (Fig. 1C). These observations indicate that loss of AGO1 has both a positive and negative impact on gene expression (Supplemental Fig. S2c). We further extended our analysis to find a possible correlation between perturbed transcripts and deregulated miRNAs. To this, we compared small RNA-seq data (Supplemental Fig. S2d) in control, and AGO1 depleted cells. The majority (95\%) of perturbed mRNAs were not direct targets of differentially expressed miRNAs (Supplemental Fig. S2e). Moreover, we did not observe any significant correlation between the effect of down- and up-regulated miRNAs and the expression of predicted targets (Supplemental Fig. S2f-i). To discriminate between directly and indirectly regulated genes, we integrated CAGE- 
seq with AGO1 binding sites on chromatin (ChIP-seq). First, we examined AGO1 genomic distribution by ChIP-seq in HepG2 cells (Supplemental Fig. S3a-b, and see supplemental results). As previously reported (Allo et al. 2014) we found AGO1 enrichment across many active sites such as enhancers, promoters and also other genic regions (Supplemental Fig. S3c-d). Among all the differentially expressed genes, we observed AGO1 binding at about 29\% (274) genes, but only $16 \%$ (43) of these genes overlapped with AGO1 peaks at their promoters. In contrast, for the majority of perturbed genes $(71 \%)$ we did not detect AGO1 at their promoters or within the coding region (Fig. 1D). However, we observed a clear enrichment of AGO1 binding at the predicted enhancers located within $<50 \mathrm{~kb}$ of all the differentially expressed genes (Fig. 1E). We further categorized AGO1 peaks into three classes, i.e., promoter, proximal and distal regions and observed a higher enrichment at distal sites (Fig. 1F and Supplemental Fig. S3e). As expected, these AGO1 enriched regions showed high overlap with ENCODE HepG2 histone ChIP-seq datasets such as H3K4me1, H3K4me3, H3K27ac, and H3K9ac, representing active enhancers (Supplemental Fig. S3f). Next, by overlapping all transcripts from CAGE-seq with AGO1 peaks, we observed a strong correlation with RNAs produced at those sites (Fig. 1G). We found detectable levels of transcriptional activity at AGO1 bound proximal and distal regions, which represent putative enhancer RNAs (eRNA) (Fig. 1G), We also performed AGO2 ChIP-seq with a specific antibody, but we failed to obtain enough reproducible peaks (data not shown), which is consistent with a previous report (Huang et al. 2013). Furthermore, cellular fractionation followed by western-blot analysis revealed higher AGO1 enrichment compared to AGO2 and AGO3 in the chromatin-bound fraction (Supplemental Fig. S1b). Thus, the conserved association of AGO1 with active chromatin sites (Cernilogar et al. 2011; Huang et al. 2013) and the lack of its endonuclease activity, but not the RNA binding domain (Wu et al. 2008) suggested an RNA processing independent role of AGO1 in chromatin. 
Therefore, we focused our subsequent analysis only on AGO1 and its potential interacting RNA partners.

\section{Analysis of chromatin-bound AGO1 associated RNAs identifies NEAT1 IncRNA as a highly enriched component}

To clarify the involvement of RNA(s) in AGO1 nuclear function, we explored chromatinbound AGO1-associated RNA moieties in the nucleus by cross-linked RIP-seq. For maximum output of RIP-seq data, the extracted RNA molecules were separated into two fractions ( 100 nt fraction and $\sim 400 \mathrm{nt}$ fraction) and processed for deep sequencing using the Illumina platform. The two fractions of AGO1 RIP-seq data displayed similar profiles (Fig. 2A). The genome-wide mapping of the AGO1-associated RNA fractions ( 100 and $\sim 400 \mathrm{bp})$ showed enrichment of coding, non-coding and un-annotated RNA peaks (Fig. 2B-C). Additionally, we intersected AGO1-associated RNA peaks with AGO1-bound (ChIP-seq) and -unbound chromosomal regions across the genome. They showed a significant enrichment on AGO1-bound active sites (promoters and enhancers) when compared to AGO1-absent sites in the genome (Fig. 2D). Next, we identified a total of 3500 and 1854 transcripts containing approximately $50 \%$ non-coding RNAs in both 100 bp and 400 bp RIP-seq fractions respectively.

Among AGO1-associated IncRNAs, we identified NEAT1 IncRNA as the most significantly enriched major partner of chromatin-bound AGO1 in both RNA fractions (Fig. 2E). NEAT1 IncRNA is an essential structural component of paraspeckle nuclear bodies. Along with NEAT1, we also found enriched transcripts of other paraspeckle components such as PSPC1, HNRNPH1 and FUS (Fig. 2E). These results suggested that the nuclear AGO1 associates with paraspeckles and its major component NEAT1 IncRNA. 


\section{AG01 interacts with NEAT1 and other essential paraspeckle proteins and is required for paraspeckle integrity}

Given the enrichment of NEAT1 in AGO1-bound chromatin fraction, we sought to verify whether AGO1 is an integral component of paraspeckle nuclear bodies. Along with NEAT1 short isoform (3.7-kb), we found a higher number of reads coverage on NEAT1_2 (23-kb) (Fig. 3A), which is essential for de novo assembly of paraspeckles. The direct interaction between AGO1 and both NEAT1 isoforms (NEAT1_1 and NEAT1_2) was confirmed by UV cross-linking and immunoprecipitation followed by qPCR (Fig. 3B and Supplemental Table S1). Immunofluorescence combined with RNA FISH revealed AGO1 co-localization with NEAT1 IncRNA in paraspeckles (Fig. 3C), but not AGO2 (Supplemental Fig. S1d). The specificity of AGO1 detection was confirmed by observing signal disappearance upon AGO1 depletion (Supplemental Fig. S1i). Also, we used soluble nuclear, and chromatin extracts of stable cell lines expressing AGO1 and AGO2 fused with C-terminal Flag- and HA-epitope tags (named e-AGO1 and e-AGO2) for double-immunoaffinity purification (Supplemental Fig. S4a). The essential paraspeckle proteins were identified explicitly in the e-AGO1 but not e-AGO2 nuclear and chromatin complexes by mass spectrometry and western blotting (Fig. 3D-E and Supplemental Fig. S4b). We next conducted NEAT1 ChIRP-western blot experiment to confirm the interaction of AGO1 with NEAT1 (Supplemental Fig. S5a-b). NEAT1 ChIRP followed by immunoblotting further proved the presence of AGO1 along with paraspeckle proteins (SFPQ and NONO) in the NEAT1 associated proteins (Supplemental Fig. S5cd). These results indicate that AGO1 is stably associated with paraspeckle.

Our AGO1 ChIP-seq peaks showed enrichment at the promoter of the NEAT1 gene (Fig. $3 G$ ), indicating the NEAT1 locus to be a direct target of AGO1. Indeed, upon AGO1 depletion by CAGE-seq, we observed up-regulation of the NEAT1 transcript. Importantly, by RT-qPCR we confirmed the induction of both NEAT1_1 and NEAT1_2) in AGO1 
knockdown cells (Fig. $3 \mathrm{H}$ ). The expression of NEAT1 is an essential early step in paraspeckle formation, thus we asked whether AGO1 is involved in paraspeckle assembly. We examined the paraspeckle integrity after AGO1 knockdown by analyzing co-localization of NEAT1 with SFPQ an essential paraspeckle component. Despite increased NEAT1 RNA-FISH signal, we observed a diffuse SFPQ signal in $>60 \%$ of siAGO1 cells, affecting paraspeckle integrity (Fig. 3I-J). Furthermore, by ChIRP-western blot we checked the effect of AGO1 depletion on the interaction of other essential paraspeckle proteins with NEAT1. In AGO1 depleted cells, immunoblot analyses of NEAT1 associated proteins showed a reduction in the level of crucial paraspeckle components (NONO, HNRNPK, and SFPQ) (Supplemental Fig. S5e). In summary, AGO1 interacts with NEAT1 IncRNA and other paraspeckle components, and its depletion impacts NEAT1 expression and formation of intact paraspeckles.

\section{AG01 depletion alters chromatin interactions specifically in AG01 bound regions}

Since AGO1 binds specific gene loci and it is necessary for intact paraspeckle formation, we sought to investigate the role of AGO1 in higher order chromatin organization. To this end, we performed an unbiased genome-wide chromatin conformation analysis using HiC in siCtrl and siAGO1 HepG2 cells (Supplemental Fig. S6). At the global level, the chromosomal interaction frequency heatmaps for each chromosome displayed similar patterns in both siAGO1 and siCtrl cells (Fig. 4A-B). To gain deeper insight into differential interaction frequencies between siCtrl and siAGO1 cells, we compared normalized HiC data (siAGO1 versus siCtrl) with the R package diffHiC (Lun and Smyth 2015). In this case, significant differences in genome-wide chromatin interactions between siAGO1 and siCtrl cells were revealed (Fig. 4C). Upon AGO1 depletion, we observed extensive changes in both long-range and short-range interaction frequency across the genome (Fig. 4C and Supplemental Fig. S7a). Significant differences were detected in siAGO1 cells in both intra- and inter-chromosomal interactions (Fig. 4D and 
Supplemental Fig. S7b-c). Next, we asked whether changes in chromosomal interactions were correlated with AGO1 binding sites. We found that $93 \%$ of AGO1 binding sites (16,566 AGO1 peaks) overlapped with differential interacting regions at a genome-wide level (Fig. 4E). We then calculated the difference in the number of differential interactions between AGO1 enriched and without AGO1 binding 20-kb bins. We observed a significantly (t-test $<0.05$ ) higher number of differential interactions between bin-pairs containing AGO1 binding sites than without AGO1 binding (Fig. 4F). In particular, upon AGO1 depletion we observed a significant decrease in chromosomal interaction frequency among AGO1 binding sites, with a simultaneous gain in chromatin interactions at other genomic loci (Fig. 4G). Overall, these data suggest that AGO1 binding at genomic regulatory sites influences higher order chromatin interactions.

\section{AG01 depletion perturbs chromatin compartments and TADs organization}

Globally, the genome is partitioned into active (open, A-type) and inactive (closed, Btype) compartments (Lieberman-Aiden et al. 2009; Rao et al. 2014). Thus, we first investigated the effects of AGO1 depletion on the A/B chromatin compartmentalization. We defined chromatin compartments (A and $B$ ) using the first principal component (PC1) by eigenvector analysis (Zhang et al. 2012). To further demarcate A/B chromatin compartments, we also intersected expressed genes (identified by CAGE-seq) with eigenvector values. We then compared the genome-wide compartments between siCtrl and siAGO1 cells at $100 \mathrm{~kb}$ resolution. We observed changes in the distribution of open and closed compartments in siAGO1 compared to siCtrl cells (Fig. 4H). Globally, the siAGO1 displayed a highly mixed $A$ and $B$ compartmentalization (Fig. $4 \mathrm{H}$ and Supplemental Fig. S8a). Notably, $24 \%$ of the siAGO1 genome showed compartments switching, which predominantly occurred in the open A-type compartment (Fig. 4I).

To examine the effect on TAD organization, we first identified 3,143 and 3,593 TADs in siCtrl and siAGO1 cells respectively using TADbit tool (Serra 2016). We consistently 
found that in siAGO1 TADs size was smaller compared to siCtrl cells (t-test, FDR $<0.05$ ) (Supplemental Fig. S8b). Then, by visualizing the topological domains in AGO1-depleted cells, we frequently observed that larger domains found in siCtrl cells were divided into smaller sub-domains (Fig. 4J). Additionally, we found that $25 \%$ of AGO1 binding sites (detected by ChIP-seq) overlapped with TAD boundaries identified at $100-\mathrm{kb}$ resolution (Supplemental Fig. S8c). Finally, although there are differences in the numbers and size of TADs in siAGO1 cells, TAD boundaries between siCtrl and siAGO1 cells were largely maintained (Supplemental Fig. S8d). These results suggest that AGO1 contributes to the maintenance of TADs and chromatin compartmentalization.

\section{AG01 dependent topological changes correlate with differential gene expression}

To determine whether AGO1 dependent changes in chromatin topological structure correlated with differential gene expression, we applied an integrative approach by combining transcriptome (CAGE-seq) with Hi-C and AGO1 ChIP-seq analyses. We first examined the effect of changes in compartmentalization on gene expression. We found that in siAGO1 cells $20 \%$ of differentially expressed genes were associated with disorganized chromatin compartments (Fig. 5A-C). Notably, all deregulated genes were present in the active (A) compartments in wild-type cells. Furthermore, the majority of deregulated genes that reside within topological domains, or near domain borders, overlapped with extensive changes in chromosomal interactions following AGO1 knockdown (Fig. 5D). Next, we classified all deregulated genes (FDR $\leq 0.05$ and log2FC >1.2) located within differential interacting bins (DI bin) into two categories based on correlation with either i) compartment switching or ii) changes in TADs configuration (Fig. $5 E)$. We further validated by RT-qPCR, the changes in expression of selected perturbed genes (AGO1 KD CAGE-seq) located within differentially interacting bins (AGO1 KD HiC) (Supplemental Fig. S9a-d). Altogether, around $80 \%$ of deregulated genes are 
correlated with differential interactions, and a subset of these genes is affected by compartment transitions upon AGO1 depletion.

\section{NEAT1 depletion impacts AG01 paraspeckle localization and chromatin architecture}

To understand the functional link between NEAT1 and AGO1, we asked whether NEAT1 is necessary and sufficient for AGO1 nuclear paraspeckle localization. First, we examined the nuclear localization of AGO1 upon transient depletion of NEAT1 by antisense oligo (ASO) that targets both NEAT1 isoforms. Strikingly, we observed a marked disappearance of AGO1 nuclear paraspeckle signals in NEAT1 depleted cells (Fig. 7A). Next, by using CRISPR/Cas9 we generated NEAT1 knocked-out (KO) human HAP1 (near-haploid) cell line (Fig. 6A). We used the HAP1 cell line because of the ease of genome editing in these cells. By combining NEAT1 RNA FISH with SFPQ immunofluorescence, we confirmed the complete disappearance of paraspeckles in the selected NEAT1-KO HAP1 cell lines (Supplemental Fig. S10a). Consistent with NEAT1 transient depletion, we observed a substantial adverse effect on AGO1 nuclear localization also in NEAT1-KO cells (Fig. 6B).

NEAT1 was reported to be enriched on active chromatin by CHART-seq in human cells (West et al. 2014). Our data show that AGO1 co-localizes with NEAT1 across active sites and its depletion affects paraspeckle integrity and chromatin organization. We observed that around $94 \%$ of NEAT1 CHART-seq peaks overlapped with AGO1 binding (ChIP-seq) at active sites (Fig. 6C). This finding suggests that the combinatorial action of NEAT1 paraspeckles and nuclear AGO1 is required for correct genome architecture.

To test this hypothesis, we examined how the loss of NEAT1-paraspeckles affects chromatin organization using Hi-C in wild-type (WT) and NEAT1-KO HAP1 cell lines. We determined significant interaction matrices with the HiC-Pro pipeline (Servant et al. 2015) (Supplemental Fig. S10b-e), differential interactions by diffHiC (Lun and Smyth 
2015), and (A/B) compartment analysis by principal components. The differential Hi-C analysis identified 3,567 bins showing a significant $(F D R<0.05, \log F C>1.2)$ gain in intra-chromosomal interactions in NEAT1-KO cells.

Furthermore, comparing genome-wide compartments between NEAT1-KO and WTHAP1 cells identified significant changes in A/B chromatin compartments (Fig. 7D). Notably, we observed switching of A to B compartments (Fisher's test, FDR < 0.05 ) in the majority of the chromosomes (Fig. 6D). We also found B to A compartment transition across multiple regions, specifically on chromosome 2, 4, and 21 (Fig. 6D). As an example, the PC1 values illustrate the B to A compartment switching on chromosome 21 between WT and NEAT1-knockout HAP1 in Fig.6E-F. Next, we checked the effect of NEAT1-knockout on TADs. Similar to what observed in AGO1 depleted cells, also in this case we detected "split or fused" topologically associated domains (TADs) configuration, as illustrated in one example region on chromosome 16 (Fig. 6G).

\section{Discussion}

In this work, we report a link between nuclear AGO1, NEAT1 IncRNA, paraspeckles formation, and higher-order chromatin topological structure. The role of RNA as an essential component of the nuclear architecture has been recognized for a long time (Holmes et al. 1972; Nickerson et al. 1989). Recent paradigmatic works showed Xist (Cerase et al. 2015) and Firre (Hacisuleyman et al. 2014) IncRNAs to mediate both cisand trans-chromosomal interactions. Furthermore, CoT1 repeat-derived RNA fraction was shown to be essential for the integrity of chromatin organization (Hall et al. 2014). Our RIP-seq analysis identified several RNA moieties that are associated with nuclear AGO1, including IncRNAs, mRNAs and short RNAs. While we do not exclude binding to short RNAs, because of the association of AGO1 with active regulatory cis-elements our work focused on other RNA moieties and in particular IncRNA, as a potential bridge 
between AGO1, chromatin association, and gene expression. Among all, NEAT1 IncRNA resulted to be the most represented one. NEAT1 IncRNA is the key organizer of paraspeckles, containing various RNAs and RNA binding proteins (RBPs) (Prasanth et al. 2005; Hirose et al. 2014; Imamura et al. 2014). Indeed the data presented revealed: I. AGO1 co-localization with NEAT1 containing paraspeckles, II. AGO1 association with essential paraspeckle components, III. AGO1 NEAT1 direct binding (ChIRP, CLIP), IV. impact on paraspeckle integrity upon AGO1 knockdown V. loss of AGO1 paraspeckles localization upon NEAT1 depletion.

Along with NEAT1, we also identified MALAT1 IncRNA in our RIP-seq and CLIP analysis. Also, AGO1 binds to the promoter of both NEAT1 and MALAT1 genes that are located adjacent to one another on chromosome11. MALAT1 and NEAT1 IncRNAs localize to distinct nuclear bodies the nuclear speckles and paraspeckles respectively. These nuclear bodies often localized adjacent to one another in the nucleus (Fox et al. 2002) and also share essential protein components, like PSF and NONO (Saitoh et al. 2004). The NEAT1 IncRNA has also been shown to localize to nuclear speckles upon inhibition of transcription elongation (Sunwoo et al. 2009). The significant number of genomic loci that are co-enriched by both NEAT1 and MALAT1 (West et al. 2014) also overlapped with AGO1 binding sites. These observations suggest a significant overlap between NEAT1, MALAT1, and AGO1 nuclear function. Further work should investigate the cross-talk between speckle and paraspeckle and its impact on 3D genome organization in AGO1 depleted cells.

The mechanistic explanation of the impact of AGO1 depletion on nuclear and higher order chromatin organization remains to be understood. Our findings show that AGO1 interacts with both NEAT1 TSS and NEAT1 IncRNA and its depletion induces NEAT1 over-expression but adversely affect paraspeckle formation indicates that AGO1 impacts both NEAT1 expression and paraspeckles assembly. The disruption of genomic 
compartments and TAD boundaries may lead to deregulated gene expression (Nora et al. 2012; Phillips-Cremins et al. 2013; Seitan et al. 2013; Barutcu et al. 2015). AGO1knockdown CAGE-seq analysis shows that the majority of gene expression changes correlate with perturbed topologically interacting sites and alterations in TAD structure. The differential expression of various non-coding RNAs (Isoda et al. 2017) including NEAT1 may contribute to topological organization. Consistently, the effect of AGO1 depletion, Hi-C analysis in NEAT1-KO cells reveals similar changes in higher-order chromatin architecture. A recent report showed a link between phase-separation and NEAT1-dependent paraspeckles assembly (Yamazaki et al. 2018). Thus, it is tempting to speculate that AGO1-NEAT1 IncRNA interaction might regulate the differential aggregation states of specific cis-regulatory elements with impact on transcriptional output.

Regarding other AGO proteins, currently, it is unclear whether different AGO proteins (AGO1-4) might play a similar function in the nucleus. AGO1 depletion appears to increase AGO2 nuclear levels and also to affect the nuclear redistribution of other RNAi factors (Matsui et al. 2015). Our data show that compared to AGO2-3, AGO1 proteins mostly enrich in the chromatin fractions. Moreover, unlike AGO1, AGO2 ChIP-seq analysis does not detect widespread genomic distribution (Huang et al. 2013). While we cannot exclude any technical problems related to the ChIP efficiency of AGO2 antibody, the difference in bulk chromatin binding may reflect AGO2 peripheral nuclear localization (Huang et al. 2013). Notably, a recent study (van Eijl et al. 2017) reported about the cross-reactivity of another AGO2 antibody (11A9) with SMARCC1, which was previously used for ChIP (Ameyar-Zazoua et al. 2012) and protein immunoprecipitation (Carissimi et al. 2015). Therefore, the nuclear function and genome-wide association of AGO2 remains controversial. However, direct or indirect mechanistic evidence that AGO2/3 would compensate for AGO1 nuclear function remain to be reported. Additionally, our 
data show that the essential paraspeckle proteins specifically associate with AGO1 but not AGO2 nuclear complexes, indicating different functions for AGO1 and AGO2 in the nucleus. Importantly, in contrast to AGO2 (Meister et al. 2004) and AGO3 (Park et al. 2017), human AGO1 does not contain a functional slicing domain (Wu et al. 2008). Thus its nuclear function appears to be independent of RNA-processing, but instead, it depends on RNA binding.

Finally, our data demonstrate that depletion of AGO1 or NEAT1 leads to convergent phenotypic consequences namely widespread alterations of fundamental higher-order genomic compartmentalization and TADs organization (Fig. 7). Notably, there is a strong link between overexpression of NEAT1-IncRNA and several aggressive types of cancer (Chakravarty et al. 2014; Chen et al. 2015; Ma et al. 2016) that also display dramatic alterations in 3D genome organization (Barutcu et al. 2015; Achinger-Kawecka et al. 2016; Taberlay et al. 2016). The reported connection with AGO1 provides a novel insight towards understanding NEAT1-dependent mechanism operating in the development of this disease possibly via nuclear architecture.

\section{Methods}

\section{Cell culture}

HepG2 and HEK-293 cells were cultured in EMEM medium (Sigma, Cat \# M0643) supplemented with 10\% FBS (Invitrogen, Cat \# 26140-079), and HAP1 cells were grown in Iscove's Modified Dulbecco's Medium (IMDM, GIBCO, Cat.No. 12440-053) with 10\% FBS. 1\% penicillin and streptomycin (Euroclone, Cat \# ECB3001D) was added to culture media. Cell cultures were maintained at $37^{\circ} \mathrm{C}$ and $5 \% \mathrm{CO} 2$ (see supplemental methods for detail).

\section{Fluorescent in situ hybridization (RNA-FISH) and Immunocytochemistry}


The probes for NEAT1 IncRNA were synthesized by in-vitro transcription of antisense RNA using linearized plasmids containing a NEAT1 fragment $(+1$ to $+1,000)$. The experiments were performed as described previously (Naganuma et al. 2012; Kawaguchi et al. 2015).

\section{Chromatin fractionation}

Cells were lysed in RIPA buffer (10 mM Tris pH 8.0, 1 mM EDTA, 0.5 mM EGTA, 1\% Triton X-100, 0.1\% Sodium deoxycholate, 0.1\% SDS, $150 \mathrm{mM}$ EDTA and $0.5 \mathrm{mM}$ PMSF, $10 \mathrm{U} / \mathrm{ml}$ Superase-In, $1 \mathrm{X}$ Protease inhibitor cocktail), incubated for 30 minutes on ice, and spun at $13000 \mathrm{rpm}$ for $10 \mathrm{~min}$ to collect supernatant as total fraction (T). For chromatin fractionation, cells were lysed in CSKI buffer (10 mM Pipes pH 6.8, $100 \mathrm{mM}$ $\mathrm{NaCl}, 1 \mathrm{mM}$ EDTA, $300 \mathrm{mM}$ Sucrose, $1 \mathrm{mM} \mathrm{MgCl}$, $1 \mathrm{mM}$ DTT, 0.5\% Triton X-100, 10 $\mathrm{U} / \mathrm{ml}$ Superase-In, $1 \mathrm{X}$ Protease inhibitor cocktail) for $15 \mathrm{~min}$ on ice (vortexed occasionally) and spun at $3000 \mathrm{rpm}$ for $5 \mathrm{~min}$ to remove the soluble fraction (S). Pellet was resuspended in CSK II buffer (10 mM Pipes pH 6.8, $50 \mathrm{mM} \mathrm{NaCl,} 300$ mM Sucrose, $6 \mathrm{mM} \mathrm{MgCl}_{2}, 1 \mathrm{mM} \mathrm{DTT}$ ), treated with DNase I (Promega, M610A) for 25 min at $30^{\circ} \mathrm{C}$, and followed by extraction with $250 \mathrm{mM}\left(\mathrm{NH}_{4}\right)_{2} \mathrm{SO}_{4}$ for $10 \mathrm{~min}$. The extract was centrifuged at $1200 \mathrm{~g}$ for $10 \mathrm{~min}$ at $4^{\circ} \mathrm{C}$ to collect the supernatant as chromatin bound fraction (CB).

\section{nanoCAGE-seq}

After cellular fractionation of HepG2 cells as described above, Trizol was added to the total and chromatin bound fractions for RNA extraction. Samples were processed for nanoCAGEseq as described previously (Salimullah et al. 2011).

\section{ChIP-seq}

HepG2 cells were cross-linked with $2 \%$ formaldehyde on shaking platform for 12 min at room temperature. The reaction was quenched with $125 \mathrm{mM}$ of glycine and cells were collected by scraping. The pellet was further processed by incubating in lysis buffer ( 5 
$\mathrm{mM}$ HEPES/KOH pH 8.0, $85 \mathrm{mM} \mathrm{KCl,} \mathrm{0.5 \%} \mathrm{NP-40,} 0.5 \mathrm{mM}$ PMSF) for $30 \mathrm{~min}$ on ice. Pelleted nuclei were resuspended in shearing buffer $(50 \mathrm{mM}$ Tris/ $\mathrm{HCl} \mathrm{pH}$ 8.0, $1 \mathrm{mM}$ EDTA, $0.1 \%$ SDS, $0.5 \%$ DOC, $0.5 \mathrm{mM}$ PMSF), passed through $1 \mathrm{ml}$ syringe for $10-15$ times, and sonicated with Diagenode Bioruptor (total 3 cycles for 7 min each with settings $30 \mathrm{sec}$ ON and $30 \mathrm{sec}$ OFF at maximum amplitude). To remove debris, sonicated samples were spun at $16000 \times \mathrm{xg}$ for $20 \mathrm{~min}$ at $4^{\circ} \mathrm{C}$. Supernatant was collected and chromatin DNA fragment size (average $500 \mathrm{bp}$ ) was checked after decrosslinking at $65^{\circ} \mathrm{C}$ for $4 \mathrm{hrs}$ on $2 \%$ agarose gel. Chromatin suspension was mixed with $1 \mathrm{X}$ IP buffer (1 $\mathrm{mM}$ Tris/HCl pH 7.4, 0.1 mM EDTA, 0.1\% Triton X-100, 0.05\% DOC and $150 \mathrm{mM} \mathrm{NaCl}$, 0.5 mM PMSF), AGO1 antibody (Wako, Clone 2A7) and rotated overnight on a rocker wheel at $4^{\circ} \mathrm{C}$. Immuno-complexes were captured with Dyna beads Protein G (Invitrogen) for $2 \mathrm{hrs}$ on a rocker wheel at $4^{\circ} \mathrm{C}$. Further, beads were washed with $2 \mathrm{X}$ Low Salt buffer (20 mM Tris/HCl pH 8.0, 2 mM EDTA, 0.1\% SDS, 1\% Triton X-100, $150 \mathrm{mM} \mathrm{NaCl}, 0.5$ mM PMSF), 2X High Salt buffer (20 mM Tris/HCl pH 8.0, 2 mM EDTA, 0.1\% SDS, 1\% Triton X-100, $500 \mathrm{mM} \mathrm{NaCl}, 0.5 \mathrm{mM}$ PMSF), 1X LiCl buffer (10 mM Tris/HCl pH8.0, 10 mM EDTA, 1\% NP-40, $250 \mathrm{mM} \mathrm{LiCl,} 0.5 \mathrm{mM}$ PMSF), and 1X TE (1 mM Tris/HCl pH 8.0, $1 \mathrm{mM}$ EDTA). Finally, immunocomplexes were eluted $(1 \mathrm{mM}$ Tris/HCl $\mathrm{pH}$ 8.0, $10 \mathrm{mM}$ EDTA, $1 \%$ SDS) at $65^{\circ} \mathrm{C}$ for $20 \mathrm{~min}$, cross-links were reversed at $65^{\circ} \mathrm{C}$ overnight, treated with RNase $\mathrm{A}$, proteinase $\mathrm{K}$ and then DNA was extracted with Phenol:Chloroform:Isoamyl alcohol (25:24:1). The extracted ChIP-DNA was processed for high-throughput library preparation.

\section{AG01 RIP from chromatin fraction}

The AGO1 RIP-seq was performed following the above ChIP experiment until the last washing step as described in the protocol. The whole procedure was carried out at $4^{\circ} \mathrm{C}$ and all the buffers were prepared in DEPC $(0.1 \%(\mathrm{v} / \mathrm{v})$ and supplemented with Superase-In (Ambion - AM2696) 10U/ml. After proteinase $\mathrm{K}$ treatment $(0.4 \mathrm{mg} / \mathrm{ml}$ ) on 
beads at $37^{\circ} \mathrm{C}$ for $30 \mathrm{~min}$, the samples were processed for the reverse cross-linking at $65^{\circ} \mathrm{C}$ for 2 hrs. Finally, the RNAs were extracted using TRI reagent and processed for library preparation.

For UV cross-linking IP combined with qRT-PCR, cells were cross-linked on ice with 254 $\mathrm{nM}$ UV-C at $0.3 \mathrm{~J} / \mathrm{cm} 2$, and the rest of the experiment was performed as described previously (Sasaki et al. 2009).

\section{Preparation of $\mathrm{Hi}-\mathrm{C}$ libraries and generation of contact matrices}

Hi-C experiments were carried out as previously described (Lieberman-Aiden et al. 2009; Belton et al. 2012), with minor modifications(Schoenfelder et al. 2015). Briefly, 25 million cells were fixed with $2 \%$ formaldehyde and lysed. Following HindIII digestion and biotinylation of DNA ends, ligation was performed inside the nuclei. After de-crosslinking, the DNA was purified, sheared, and pull-down performed with streptavidin beads. Hi-C libraries were prepared for sequencing on HiSeq 4000 (Illumina). After sequencing, Fastq data were processed through HiC-Pro pipeline(Servant et al. 2015) for generating contact matrices at different resolutions. We obtained a total of around 190 million valid interaction pairs, $\sim 95$ million for siCtrl and $\sim 95$ million for siAGO1 HepG2 cells (combined replicates) (Supplemental Fig. S6a-d), the two replicates in each condition showed high degree of similarity and reproducibility (Supplemental Fig. S6e). Similarly, we obtained around 466 million valid pairs, 200 million for WT-HAP1 and 266 million for NEAT1-KO HAP1 cell lines (Supplemental Fig. S10b-c).

\section{Bioinformatics analyses}

The detail bioinformatics analyses are provided in the supplemental methods.

\section{Data access}

The high-throughput sequencing data including CAGE-seq, Small RNA-seq, ChIP-seq, RIP-seq, and Hi-C-seq have been deposited at the Sequence Read Archive (SRA, 
http://www.ncbi.nlm.nih.gov/sra/), which is hosted at the NCBI, under the SRA accession number SRP115598 (BioProject ID\# PRJNA398595).

\section{Acknowledgments}

We are grateful to Hakan Ozadam and Johan Gibcus from Job Dekker group (University of Massachusetts Medical School, USA) for initial help in Hi-C analysis; Riccardo Aiese Cigliano (Sequentia Biotech) for help in bioinformatic analysis; Ana Maria Suzuki (RIKEN) for help in CAGE-seq; Heno Hwang (scientific illustrator) at KAUST for his help in drawing the image (Figure-8); Christian Froekjaer Jensen for critical reading of the manuscript; KAUST Bioscience Core Lab for providing sequencing facility. The work was supported by EPIGEN-CNR (Italian Ministry of University and Research) and King Abdullah University of Science and Technology (KAUST) to V.O. The grants from the MEXT of Japan to TH (26113002 and 17H03630). The grant for Joint Research Program of IGM, Hokkaido University.

\section{Author contributions}

M.S conceived this study, designed and performed experiments, analyzed the data and wrote the manuscript with input from all the authors. K.M.P designed and performed experiments. S.A.A contributed in Hi-C experiments. A.F. contributed in RIP-seq experiments. M.T and H.K. performed computational analyses of RIP-seq, CAGE-seq and ChIP-seq data. Y.G and L.S performed computational analyses of RIP-seq, ChIPseq and CAGE-seq data. T.Y provided the HAP1 cells (NEAT1 knockout and wild type). T.M and T.Y contributed in the RNA FISH experiments. B.F helped in western blotting. T.H conceived and designed the experiments related to paraspeckles. P.C and H.K. produced and analyzed the CAGE-seq experiment. V.O. conceived this study, designed experiments, and wrote the manuscript. 


\section{Competing interests}

Authors declare no competing interests.

\section{References}

Achinger-Kawecka J, Taberlay PC, Clark SJ. 2016. Alterations in Three-Dimensional Organization of the Cancer Genome and Epigenome. Cold Spring Harb Symp Quant Biol 81: 41-51.

Agirre E, Bellora N, Allo M, Pages A, Bertucci P, Kornblihtt AR, Eyras E. 2015. A chromatin code for alternative splicing involving a putative association between CTCF and HP1alpha proteins. BMC Biol 13: 31.

Allo M, Agirre E, Bessonov S, Bertucci P, Gomez Acuna L, Buggiano V, Bellora N, Singh B, Petrillo E, Blaustein M et al. 2014. Argonaute-1 binds transcriptional enhancers and controls constitutive and alternative splicing in human cells. Proc Natl Acad Sci U S A 111: 15622-15629.

Ameyar-Zazoua M, Rachez C, Souidi M, Robin P, Fritsch L, Young R, Morozova N, Fenouil R, Descostes N, Andrau JC et al. 2012. Argonaute proteins couple chromatin silencing to alternative splicing. Nat Struct Mol Biol 19: 998-1004.

Barutcu AR, Lajoie BR, McCord RP, Tye CE, Hong D, Messier TL, Browne G, van Wijnen AJ, Lian JB, Stein JL et al. 2015. Chromatin interaction analysis reveals changes in small chromosome and telomere clustering between epithelial and breast cancer cells. Genome Biol 16: 214.

Belton JM, McCord RP, Gibcus JH, Naumova N, Zhan Y, Dekker J. 2012. Hi-C: a comprehensive technique to capture the conformation of genomes. Methods $\mathbf{5 8}$ : 268-276. 
Bouwman BA, de Laat W. 2015. Getting the genome in shape: the formation of loops, domains and compartments. Genome Biol 16: 154.

Carissimi C, Laudadio I, Cipolletta E, Gioiosa S, Mihailovich M, Bonaldi T, Macino G, Fulci V. 2015. ARGONAUTE2 cooperates with SWI/SNF complex to determine nucleosome occupancy at human Transcription Start Sites. Nucleic Acids Research 43: 1498-1512.

Cerase A, Pintacuda G, Tattermusch A, Avner P. 2015. Xist localization and function: new insights from multiple levels. Genome Biology 16.

Cernilogar FM, Onorati MC, Kothe GO, Burroughs AM, Parsi KM, Breiling A, Lo Sardo F, Saxena A, Miyoshi K, Siomi H et al. 2011. Chromatin-associated RNA interference components contribute to transcriptional regulation in Drosophila. Nature 480: 391-395.

Chakravarty D, Sboner A, Nair SS, Giannopoulou E, Li R, Hennig S, Mosquera JM, Pauwels J, Park K, Kossai M et al. 2014. The oestrogen receptor alpha-regulated IncRNA NEAT1 is a critical modulator of prostate cancer. Nat Commun 5: 5383.

Chen X, Kong J, Ma Z, Gao S, Feng X. 2015. Up regulation of the long non-coding RNA NEAT1 promotes esophageal squamous cell carcinoma cell progression and correlates with poor prognosis. Am J Cancer Res 5: 2808-2815.

Chujo T, Yamazaki T, Kawaguchi T, Kurosaka S, Takumi T, Nakagawa S, Hirose T. 2017. Unusual semi-extractability as a hallmark of nuclear body-associated architectural noncoding RNAs. Embo Journal 36: 1447-1462.

Clemson CM, Hutchinson JN, Sara SA, Ensminger AW, Fox AH, Chess A, Lawrence JB. 2009. An architectural role for a nuclear noncoding RNA: NEAT1 RNA is essential for the structure of paraspeckles. Mol Cell 33: 717-726.

Delest A, Sexton T, Cavalli G. 2012. Polycomb: a paradigm for genome organization from one to three dimensions. Current Opinion in Cell Biology 24: 405-414. 
Dixon JR, Selvaraj S, Yue F, Kim A, Li Y, Shen Y, Hu M, Liu JS, Ren B. 2012.

Topological domains in mammalian genomes identified by analysis of chromatin interactions. Nature 485: 376-380.

Fox AH, Lam YW, Leung AK, Lyon CE, Andersen J, Mann M, Lamond AI. 2002.

Paraspeckles: a novel nuclear domain. Curr Biol 12: 13-25.

Hacisuleyman E, Goff LA, Trapnell C, Williams A, Henao-Mejia J, Sun L, McClanahan P, Hendrickson DG, Sauvageau M, Kelley DR et al. 2014. Topological organization of multichromosomal regions by the long intergenic noncoding RNA Firre. Nature Structural \& Molecular Biology 21: 198-+.

Hall LL, Carone DM, Gomez AV, Kolpa HJ, Byron M, Mehta N, Fackelmayer FO, Lawrence JB. 2014. Stable C0T-1 Repeat RNA Is Abundant and Is Associated with Euchromatic Interphase Chromosomes. Cell 156: 907-919.

Hirose T, Virnicchi G, Tanigawa A, Naganuma T, Li R, Kimura H, Yokoi T, Nakagawa S, Benard M, Fox AH et al. 2014. NEAT1 long noncoding RNA regulates transcription via protein sequestration within subnuclear bodies. Mol Biol Cell 25: 169-183.

Holmes DS, Mayfield JE, Sander G, Bonner J. 1972. Chromosomal RNA: its properties. Science 177: 72-74.

Huang V, Zheng J, Qi Z, Wang J, Place RF, Yu J, Li H, Li LC. 2013. Ago1 Interacts with RNA polymerase II and binds to the promoters of actively transcribed genes in human cancer cells. PLoS Genet 9: e1003821.

Imamura K, Imamachi N, Akizuki G, Kumakura M, Kawaguchi A, Nagata K, Kato A, Kawaguchi $\mathrm{Y}$, Sato H, Yoneda $\mathrm{M}$ et al. 2014. Long noncoding RNA NEAT1dependent SFPQ relocation from promoter region to paraspeckle mediates IL8 expression upon immune stimuli. Mol Cell 53: 393-406. 
Isoda T, Moore AJ, He Z, Chandra V, Aida M, Denholtz M, Piet van Hamburg J, Fisch KM, Chang AN, Fahl SP et al. 2017. Non-coding Transcription Instructs Chromatin Folding and Compartmentalization to Dictate Enhancer-Promoter Communication and T Cell Fate. Cell 171: 103-119 e118.

Joshua-Tor L, Hannon GJ. 2011. Ancestral roles of small RNAs: an Ago-centric perspective. Cold Spring Harb Perspect Biol 3: a003772.

Kagey MH, Newman JJ, Bilodeau S, Zhan Y, Orlando DA, van Berkum NL, Ebmeier CC, Goossens J, Rahl PB, Levine SS et al. 2010. Mediator and cohesin connect gene expression and chromatin architecture. Nature 467: 430-435.

Kawaguchi T, Tanigawa A, Naganuma T, Ohkawa Y, Souquere S, Pierron G, Hirose T. 2015. SWI/SNF chromatin-remodeling complexes function in noncoding RNAdependent assembly of nuclear bodies. Proc Natl Acad Sci U S A 112: 43044309.

Lieberman-Aiden E, van Berkum NL, Williams L, Imakaev M, Ragoczy T, Telling A, Amit I, Lajoie BR, Sabo PJ, Dorschner MO et al. 2009. Comprehensive mapping of long-range interactions reveals folding principles of the human genome. Science 326: 289-293.

Lun AT, Smyth GK. 2015. diffHic: a Bioconductor package to detect differential genomic interactions in Hi-C data. BMC Bioinformatics 16: 258.

Ma Y, Liu L, Yan F, Wei W, Deng J, Sun J. 2016. Enhanced expression of long noncoding RNA NEAT1 is associated with the progression of gastric adenocarcinomas. World J Surg Oncol 14: 41.

Mao YS, Sunwoo H, Zhang B, Spector DL. 2011. Direct visualization of the cotranscriptional assembly of a nuclear body by noncoding RNAs. Nat Cell Biol 13: 95-101. 
Matsui M, Li LD, Janowski BA, Corey DR. 2015. Reduced Expression of Argonaute 1, Argonaute 2, and TRBP Changes Levels and Intracellular Distribution of RNAi Factors. Sci Rep-Uk 5.

Meister G. 2013. Argonaute proteins: functional insights and emerging roles. Nat Rev Genet 14: 447-459.

Meister G, Landthaler M, Patkaniowska A, Dorsett Y, Teng G, TuschI T. 2004. Human Argonaute2 mediates RNA cleavage targeted by miRNAs and siRNAs. Mol Cell 15: 185-197.

Moshkovich N, Nisha P, Boyle PJ, Thompson BA, Dale RK, Lei EP. 2011. RNAiindependent role for Argonaute2 in CTCF/CP190 chromatin insulator function. Genes Dev 25: 1686-1701.

Naganuma T, Nakagawa S, Tanigawa A, Sasaki YF, Goshima N, Hirose T. 2012.

Alternative 3'-end processing of long noncoding RNA initiates construction of nuclear paraspeckles. EMBO J 31: 4020-4034.

Nickerson JA, Krochmalnic G, Wan KM, Penman S. 1989. Chromatin Architecture and Nuclear-Rna. P Natl Acad Sci USA 86: 177-181.

Nora EP, Lajoie BR, Schulz EG, Giorgetti L, Okamoto I, Servant N, Piolot T, van Berkum NL, Meisig J, Sedat J et al. 2012. Spatial partitioning of the regulatory landscape of the X-inactivation centre. Nature 485: 381-385.

Park MS, Phan HD, Busch F, Hinckley SH, Brackbill JA, Wysocki VH, Nakanishi K. 2017. Human Argonaute3 has slicer activity. Nucleic Acids Research 45: $11867-$ 11877.

Phillips-Cremins JE, Sauria ME, Sanyal A, Gerasimova TI, Lajoie BR, Bell JS, Ong CT, Hookway TA, Guo C, Sun Y et al. 2013. Architectural protein subclasses shape 3D organization of genomes during lineage commitment. Cell 153: 1281-1295. 
Prasanth KV, Prasanth SG, Xuan Z, Hearn S, Freier SM, Bennett CF, Zhang MQ,

Spector DL. 2005. Regulating gene expression through RNA nuclear retention.

Cell 123: 249-263.

Rao SSP, Huntley MH, Durand NC, Stamenova EK, Bochkov ID, Robinson JT, Sanborn

AL, Machol I, Omer AD, Lander ES et al. 2014. A 3D Map of the Human Genome at Kilobase Resolution Reveals Principles of Chromatin Looping. Cell 159: 16651680.

Rinn JL, Chang HY. 2012. Genome regulation by long noncoding RNAs. Annu Rev Biochem 81: 145-166.

Saitoh N, Spahr CS, Patterson SD, Bubulya P, Neuwald AF, Spector DL. 2004.

Proteomic analysis of interchromatin granule clusters. Mol Biol Cell 15: 38763890.

Salimullah M, Sakai M, Plessy C, Carninci P. 2011. NanoCAGE: a high-resolution technique to discover and interrogate cell transcriptomes. Cold Spring Harb Protoc 2011: pdb prot5559.

Sasaki YT, Ideue T, Sano M, Mituyama T, Hirose T. 2009. MENepsilon/beta noncoding RNAs are essential for structural integrity of nuclear paraspeckles. Proc Natl Acad Sci U S A 106: 2525-2530.

Schoenfelder S, Furlan-Magaril M, Mifsud B, Tavares-Cadete F, Sugar R, Javierre BM, Nagano T, Katsman Y, Sakthidevi M, Wingett SW et al. 2015. The pluripotent regulatory circuitry connecting promoters to their long-range interacting elements.

Genome Res 25: 582-597.

Seitan VC, Faure AJ, Zhan Y, McCord RP, Lajoie BR, Ing-Simmons E, Lenhard B, Giorgetti L, Heard E, Fisher AG et al. 2013. Cohesin-based chromatin interactions enable regulated gene expression within preexisting architectural compartments. Genome Res 23: 2066-2077. 
Serra F, Baù, D., Filion, G., \& Marti-Renom, M. A. 2016. Structural features of the fly chromatin colors revealed by automatic three-dimensional modeling. bioRxiv doi:doi:10.1101/036764.

Servant N, Varoquaux N, Lajoie BR, Viara E, Chen CJ, Vert JP, Heard E, Dekker J, Barillot E. 2015. HiC-Pro: an optimized and flexible pipeline for Hi-C data processing. Genome Biol 16: 259.

Sofueva S, Yaffe E, Chan WC, Georgopoulou D, Vietri Rudan M, Mira-Bontenbal H, Pollard SM, Schroth GP, Tanay A, Hadjur S. 2013. Cohesin-mediated interactions organize chromosomal domain architecture. EMBO J 32: 3119-3129.

Sunwoo H, Dinger ME, Wilusz JE, Amaral PP, Mattick JS, Spector DL. 2009. MEN epsilon/beta nuclear-retained non-coding RNAs are up-regulated upon muscle differentiation and are essential components of paraspeckles. Genome Res 19: 347-359.

Taberlay PC, Achinger-Kawecka J, Lun AT, Buske FA, Sabir K, Gould CM, Zotenko E, Bert SA, Giles KA, Bauer DC et al. 2016. Three-dimensional disorganization of the cancer genome occurs coincident with long-range genetic and epigenetic alterations. Genome Res 26: 719-731.

Takahashi H, Lassmann T, Murata M, Carninci P. 2012. 5 ' end-centered expression profiling using cap-analysis gene expression and next-generation sequencing. Nat Protoc 7: 542-561.

van Eijl R, van den Brand T, Nguyen LN, Mulder KW. 2017. Reactivity of human AGO2 monoclonal antibody 11A9 with the SWI/SNF complex: A case study for rigorously defining antibody selectivity. Sci Rep 7: 7278.

Volpe TA, Kidner C, Hall IM, Teng G, Grewal SI, Martienssen RA. 2002. Regulation of heterochromatic silencing and histone H3 lysine- 9 methylation by RNAi. Science 297: 1833-1837. 
West JA, Davis CP, Sunwoo H, Simon MD, Sadreyev RI, Wang PI, Tolstorukov MY, Kingston RE. 2014. The long noncoding RNAs NEAT1 and MALAT1 bind active chromatin sites. Mol Cell 55: 791-802.

Wu L, Fan J, Belasco JG. 2008. Importance of translation and nonnucleolytic ago proteins for on-target RNA interference. Curr Biol 18: 1327-1332.

Yamazaki T, Souquere S, Chujo T, Kobelke S, Chong YS, Fox AH, Bond CS, Nakagawa S, Pierron G, Hirose T. 2018. Functional Domains of NEAT1 Architectural IncRNA Induce Paraspeckle Assembly through Phase Separation. Mol Cell 70: 1038-1053 e1037.

Yang LQ, Lin CR, Liu W, Zhang J, Ohgi KA, Grinstein JD, Dorrestein PC, Rosenfeld MG. 2013. ncRNA- and Pc2 Methylation-Dependent Gene Relocation between Nuclear Structures Mediates Gene Activation Programs (vol 147, pg 773, 2011). Cell 155: 478-478.

Zhang Y, McCord RP, Ho YJ, Lajoie BR, Hildebrand DG, Simon AC, Becker MS, Alt FW, Dekker J. 2012. Spatial organization of the mouse genome and its role in recurrent chromosomal translocations. Cell 148: 908-921.

Zilberman D, Cao X, Jacobsen SE. 2003. ARGONAUTE4 control of locus-specific siRNA accumulation and DNA and histone methylation. Science 299: 716-719.

Zuin J, Dixon JR, van der Reijden MI, Ye Z, Kolovos P, Brouwer RW, van de Corput MP, van de Werken HJ, Knoch TA, van IWF et al. 2014. Cohesin and CTCF differentially affect chromatin architecture and gene expression in human cells. Proc Natl Acad Sci U S A 111: 996-1001. 


\section{Figure Legends}

\section{Figure 1 AGO1 knockdown perturbs expression of coding and non-coding} transcripts. $(A-B)$ Volcano plots showing differentially expressed genes in AGO1 depleted cells, identified by CAGE-seq analysis from $(A)$ chromatin associated and $(B)$ total RNA. Significantly down-regulated (green) and up-regulated (red) genes are shown. (C) Total and chromatin associated differentially expressed coding (mRNA) and noncoding genes (FDR 0.05). (D) Integration of ChIP-seq and AGO1-knockdown CAGE-seq data classify AGO1-responsive genes into direct and indirect targets. $29 \%$ of all differentially expressed (DE) genes (from total and chromatin CAGE-seq combined) contain AGO1 binding at their promoter or intragenically, represent direct targets. $(E)$ Density plot of AGO1 ChIP-seq peaks closer than 50-kb to genes (either differentially expressed or considering all genes) centered at enhancer regions predicted by ChromHMM. (F) Bar plot shows percent enrichment of AGO1 ChIP-seq peaks at distal, promoter, and proximal regions. AGO1 peaks are highly enriched in distal regions (i.e, > 5-kb from nearest annotated TSS). A significant amount of AGO1 peaks also associate with promoter region (i.e, < 1-kb from nearest annotated TSS). (G) Density of CAGE-seq signals represents transcriptional activity at AGO1 binding regions (promoter, proximal and distal). The low level of transcriptional activity at distal regions indicates enhancer and IncRNAs.

Figure 2 Identification of chromatin-bound AG01-associated RNAs. (A) We performed RIP-seq of two RNA fractions ( $100 \mathrm{bp}$ and $\sim 400 \mathrm{bp})$ bound to chromatinextracted AGO1. Mapping sequencing reads from these two fractions display similar distributions $(B-C)$ Pie-charts show AGO1 RIP-seq peaks classification identified after mapping and peak-calling using Piranha (V1.2.1) in the two fractions: $(B) \sim 100$ bp $(C)$ 
$\sim 400$ bp. (D) The Box-plot shows enrichment of RIP-seq peaks (both 400bp and 100bp fractions) on AGO1 binding sites (ChIP-seq peaks) (Mann-Whitney test, p-value 4.4e-12) (E) Representation of highly enriched AGO1 associated chromatin bound transcripts (coding, non-coding and both).

Figure 3 AGO1 co-localizes and interacts with paraspeckle components, and its knockdown impact paraspeckles formation. $(A)$ Read coverage enrichment on both short and long isoforms of NEAT1 IncRNA in AGO1 RIP-seq fraction (100 bp and 400 bp). (B) Validation of direct interaction between AGO1 and NEAT1 IncRNA by UV crosslinking IP. After UV cross-linking, the RNAs immunoprecipitated with AGO1 IP were quantified by qRT-PCR, and the RNA enrichment (as \% input) was determined ( \pm SD from 3 experiments). IgG IP was used as mock control. (C) Localization of AGO1 and SFPQ, a known interactor, relative to paraspeckles in human HepG2 cells. AGO1 and SFPQ were detected by immunofluorescence and NEAT1 RNA-FISH was used to visualize paraspeckles. $(D-F)$ Immunopurification of FALG-HA epitope tagged e-AGO1 and e-AGO2 complexes from soluble nuclear and chromatin fractions. (D-E) Silver staining (top) of e-AGO1 (lane1) and e-AGO2 (lane2) associated proteins from $(D)$ nuclear soluble and $(E)$ chromatin fractions. The protein complexes containing e-AGO1 and e-AGO2 were purified by double immunoaffinity from soluble nuclear and chromatin extracts. Protein bands were identified by mass spectrometry analysis and the positions of molecular size markers are indicated. Paraspeckle components were identified in eAGO1 nuclear and chromatin complexes. (D-E) Western blot (lower) using HA antibody shows level of e-AGO1 (lane1) and e-AGO2 (lane2) in (D) nuclear soluble and $(E)$ chromatin complexes. $(F)$ The e-AGO1, e-AGO2 and mock control (Mock ctrl) nuclear soluble (S) and chromatin (CB) complexes (AGO1-com and AGO2-com) were analyzed by immunoblotting with the indicated antibodies. Essential paraspeckle proteins SFPQ, 
NONO, FUS, and HNRNPK are specific to e-AGO1 nuclear and chromatin complex. Double immunoaffinity was performed on untagged HEK-293 nuclear and chromatin extract as a mock control (Mock ctrl). (G) Enrichment of AGO1 ChIP-seq signal (purple) on the promoter locus (chr11) of NEAT1 IncRNA. (H) RT-qPCR analysis of NEAT1_1 and NEAT1_2 expression in siCtrl and siAGO1 HepG2 cells. Values were normalized relative to the geometric mean of $18 \mathrm{~S}$ rRNA, GAPDH, and Actin-B mRNA expression levels. Error bars indicate mean \pm s.e.m. (I) Examining the effects of AGO1 depletion on paraspeckle formation. Paraspeckle integrity was examined by SFPQ localization to NEAT1 paraspeckles using a combination of RNA-FISH and immunofluorescence. $(J)$ Quantification of the number of cells having an intact or diffuse paraspeckle signal as shown in $(I)$. Bar graph represents mean $( \pm$ s.e.m) of three technical replicates. We scored paraspeckle morphology in 670 cells (for the combined replicates) of siCtrl and siAGO1 HepG2.

Figure 4 Changes in chromatin interactions, compartments, and TADs upon AGO1

knockdown. Genome-wide chromatin conformation Hi-C analysis was performed using two replicates of siCtrl and siAGO1 cells. Representative normalized Hi-C interaction heatmaps of Chromosome 2 at $1 \mathrm{Mb}$ resolution are shown in $(A)$ siCtrl and $(B)$ siAGO1 cells. (C) Differential interaction heatmap for chromosome 2 (1Mb), showing upregulated (red) and down-regulated (blue) interacting bins. (D) Volcano plot representing differential interactions (DI) at $20 \mathrm{~kb}$ resolution. The up-regulated interactions are shown in red and the down-regulated interactions are shown in green. $(E)$ Venn diagrams showing the number of AGO1 ChIP-seq peaks overlapping with all differential interacting bins, at 20-kb resolution. $(F)$ Plot showing mean number of differential interactions calculated in 20-kb bins, based on the presence and absence of overlapping AGO1 peaks at genome-wide level (t-test, $\mathrm{p}$-value $<0.05$ and Montecarlo permutation test 
(999): p-value $\leq$ 0.002). (G) Genome browser snapshot showing Hi-C interaction frequency in siCtrl (green track), siAGO1 (orange track), and AGO1 ChIP-seq peaks (blue track) at chromosome 1 locus: 12166178-117438294. (H) Density plot showing the distribution of eigenvalues of siCtrl and siAGO1 cells at $100 \mathrm{~kb}$ resolution. siCtrl cells followed a bimodal distribution but not the siAGO1 cells. (I) Pie chart showing chromatin compartment changes between siCtrl and siAGO1 genomes. "A" and "B" represent open (active) and closed (inactive) compartments, respectively. "A->A" means no change in the compartment type between siCtrl and siAGO1 cells. "B->B" means no change in the compartment type between siCtrl and siAGO1 cells. "A->B" represents compartments that are A-type in siCtrl but changed to B-type in siAGO1. "B->A" represents compartments that are B-type in siCtrl but changed to A-type in siAGO1. Unknown represents when the compartment status is not known in either siCtrl or siAGO1. $(J)$ Visualization of normalized $\mathrm{Hi}-\mathrm{C}$ interactions from siCtrl and siAGO1 cells as twodimensional heat-maps showing TADs in both conditions. TADs found in siCtrl cells are often subdivided into two or more TADs in siAGO1 cells. An example from Chromosome 4 (locus: 73900001-74600001) is shown.

Figure 5 Integration of changes in chromatin topology with differential gene expression after AG01-depletion. (A) Pie chart represents distribution of all differentially expressed (DE) genes (identified by CAGE-seq upon AGO1 depletion) in A/B compartments between siCtrl and siAGO1 cells. "A->A" and "B->B" represent $D E$ genes that remain in the same "A" or "B" compartments respectively. "A->B" represents DE genes that switched from " $A$ " to "B" compartment and "B->A" represents DE genes that switched from "B" to "A" compartment in siAGO1 cells. $(B)$ Visualization of chromatin compartments A/B showing changes between siCtrl and siAGO1 cells (chromosome 1).

(C) Genome browser snapshot showing differentially expressed genes in the same 
region of chromosome 1 as in (b), up-regulated in red and down-regulated in blue (threshold FDR 0.05). (D) A representative plot of Chromosome 12) showing i. differential interactions up-interacting bins (red) and down-interacting bins (blue) ii. TADs configuration in siCtrl and siAGO1 cells (100-kb resolution) iii. Compartments in siCtrl and siAGO1 (100-kb resolution). The vertical dotted lines reflect compartment switching between siCtrl and siAGO1 cells. iv. Differentially expressed genes with up-regulated in purple and down-regulated in brown (threshold FDR 0.05) (E) Bar plot showing classification of differentially expressed genes into two categories based on integration with AGO1 ChIP-seq and Hi-C data (TADs and compartment switching were called at 100-kb, and differentially interacting bins at 20-kb resolution). This plot contains the number of DE genes (up-regulated and down-regulated, with FDR threshold 0.05) overlapping with AGO1-bound differentially interacting bins that either associate with different TADs configuration, and or compartment switching between siCtrl and siAGO1 cells.

Figure 6 Loss of NEAT1 affects AGO1 paraspeckle localization and higher-order chromatin organization. $(A)$ Depletion of NEAT1 by antisense oligo (ASO-NEAT1) affects AGO1 nuclear localization in HepG2 cells. GFP antisense oligo (ASO-GFP) was used as negative control. $(B)$ Similar to $(A)$ NEAT1 knockout (KO) HAP1 cell lines displayed a diffuse AGO1 signals compared to WT-HAP1. (C) Venn-diagram shows overlapping of AGO1 ChIP-seq peaks with NEAT1 CHART-seq data (Data accession\# GSM1411207 and GSM1411208). (D) Bar chart showing A/B compartment changes between NEAT1-KO and WT HAP1 genomes. "A->A" and "B->B" mean no change in the compartment A and B respectively. "A->B" represents compartments that are A-type in NEAT1-KO and B-type in WT HAP1. "B->A" represents compartments that are B-type in NEAT1-KO and A-type in WT HAP1. Significant compartment changes are shown with 
same-color hatching ( ${ }^{*}$ Fisher test, FDR<0.05). ( $\left.E-F\right)$ First eigenvector values of chromosome 21 used to define A/B chromatin compartments, positive values represent A-type (red) and negative values represent B-type (blue) compartments in WT-HAP1 (e) and NEAT1 knockout HAP1 $(F)$. Dotted lines delimit compartment borders. Active marks represent DNase-seq peaks (Data accession\#: GSM2400413 and GSM2400414) in HAP1 cell. (G) Representation of TADs and compartments in Chromosome-16 (locus $50,000,000-60,000,000$ ) identified in WT (top) and NEAT1 knockout (bottom) HAP1 cells.

Figure 7 A model that shows AGO1 together with NEAT1 IncRNA paraspeckle act as 3D genome organizers. (A) AGO1 in combination with NEAT1 IncRNA and paraspeckle proteins (PSPs) facilitates trans-chromosomal interactions and establishes an epi-genomic environment that properly maintains TADs and compartments. AGO1 or NEAT1 depleted cells show derangement in A/B compartments. AGO1 also binds to the promoter of NEAT1 and controls its expression (lower panel). The depletion of AGO1 induces NEAT1 expression and results in disorganized paraspeckles and NEAT1 IncRNA (left). Similarly, NEAT1 knockout cell lines display disorganized 3D genome structure (right). 
bioRxiv preprint doi: https://doi.org/10.1101/525527; this version posted January 20, 2019. The copyright holder for this preprint (which was not certified by peer review) is the author/funder, who has granted bioRxiv a license to display the preprint in perpetuity. It is made available under aCC-BY-NC 4.0 International license.

\section{Shuaib_Fig1}
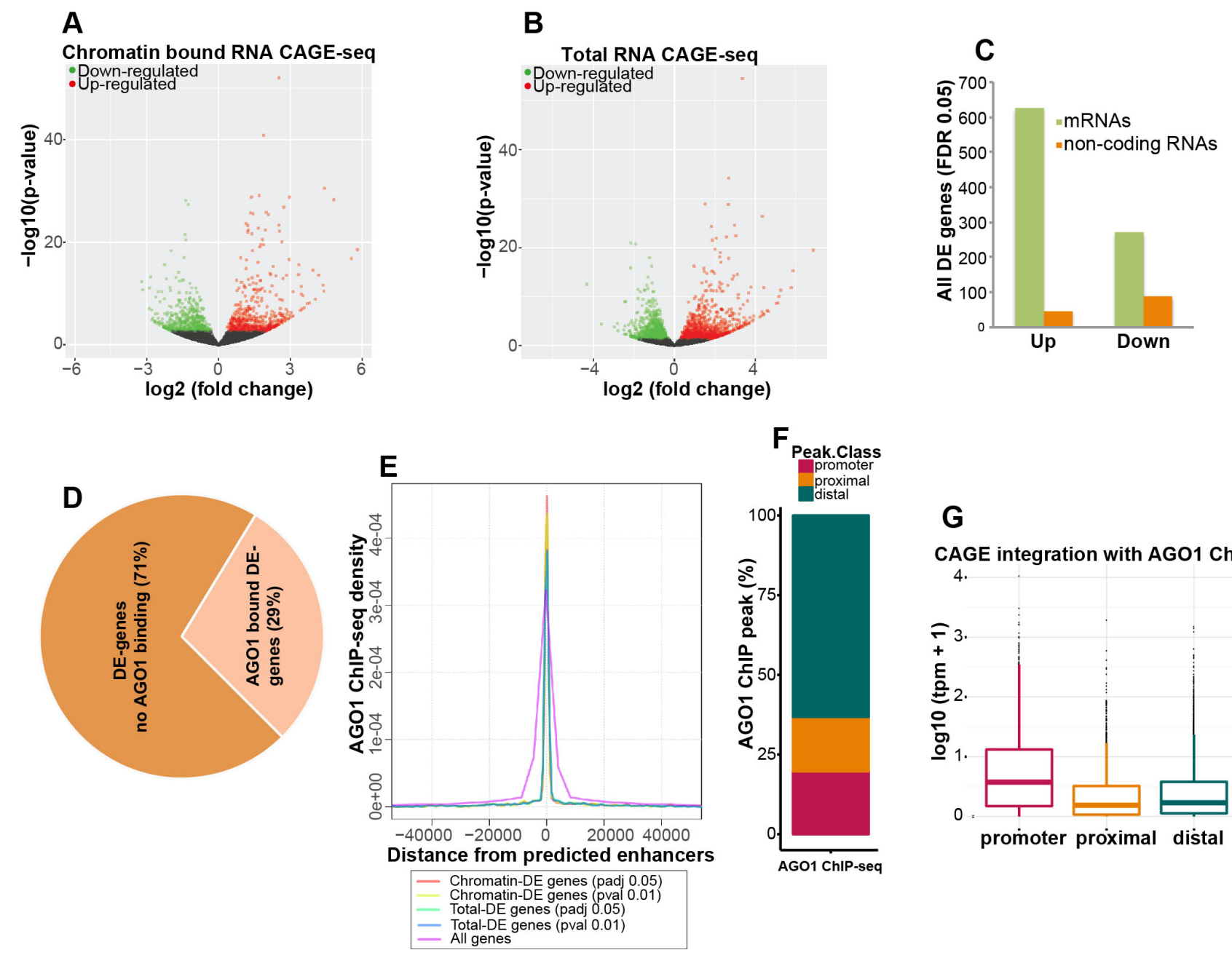

G

CAGE integration with AGO1 ChIP 4.

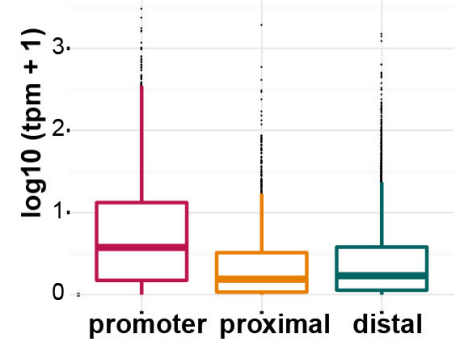


bioRxiv preprint doi: https://doi.org/10.1101/525527; this version posted January 20, 2019. The copyright holder for this preprint (which was not certified by peer review) is the author/funder, who has granted bioRxiv a license to display the preprint in perpetuity. It is made available under aCC-BY-NC 4.0 International license.

\section{Shuaib_Fig 2}

A

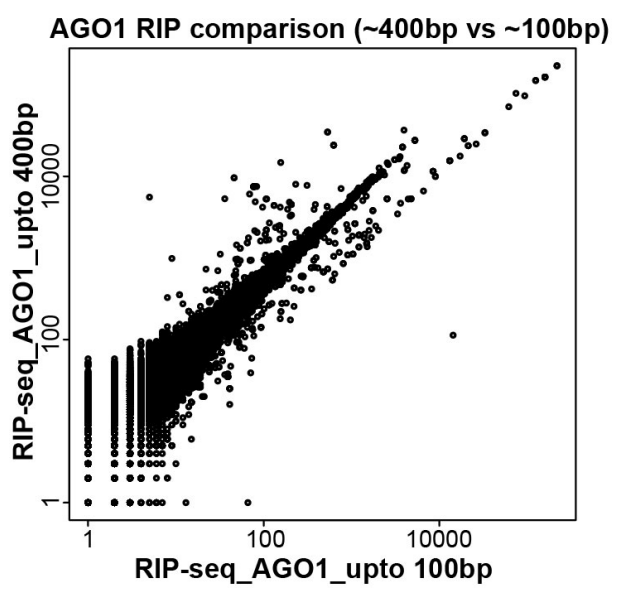

D

Overlap of RIP with AG01 ChIP-peaks 官 Without AGO1 peaks 官 With AGO1 peaks

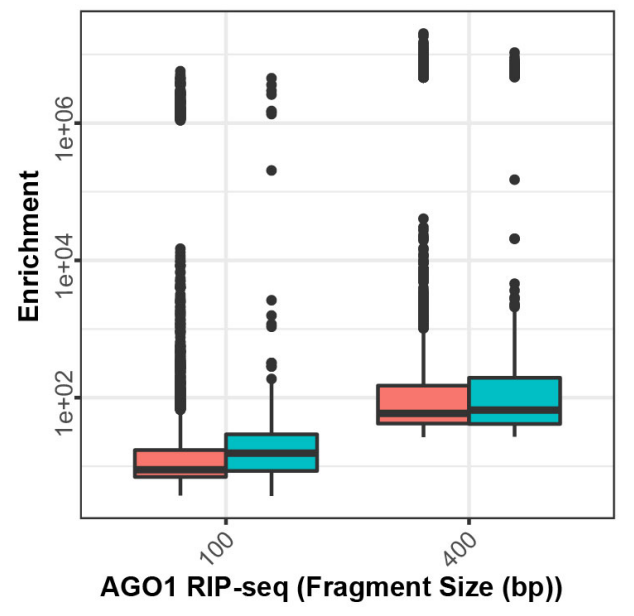

B

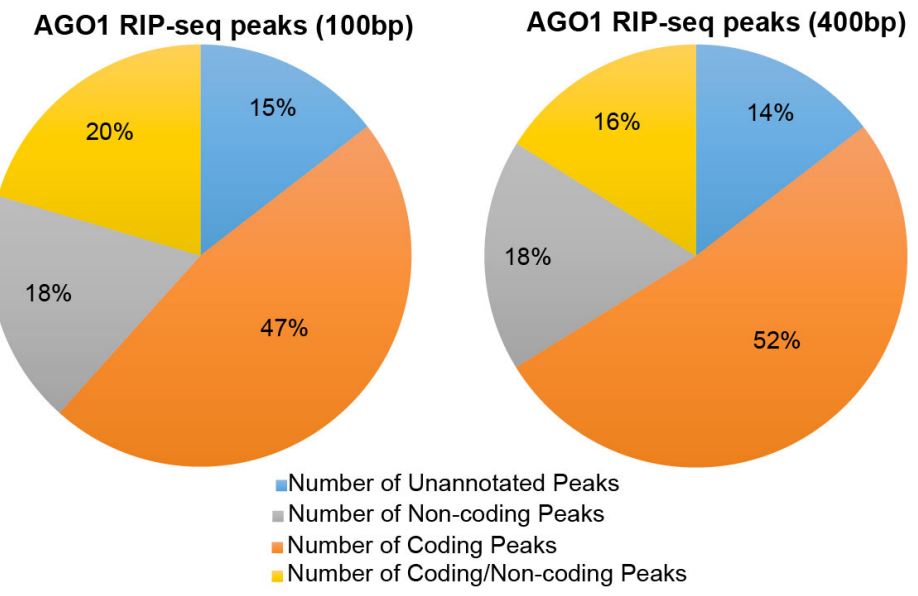

E

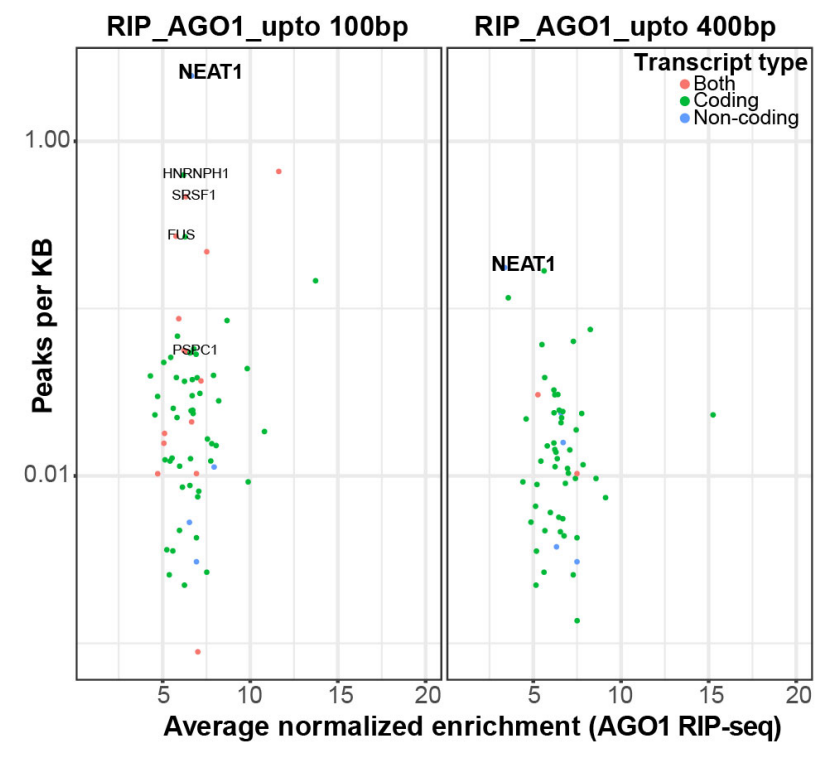


bioRxiv preprint doi: https://doi.org/10.1101/525527; this version posted January 20, 2019. The copyright holder for this preprint (which was not certified by peer review) is the author/funder, who has granted bioRxiv a license to display the preprint in perpetuity. It is made available under aCC-BY-NC 4.0 International license.

\section{Shuaib_Fig 3}

A
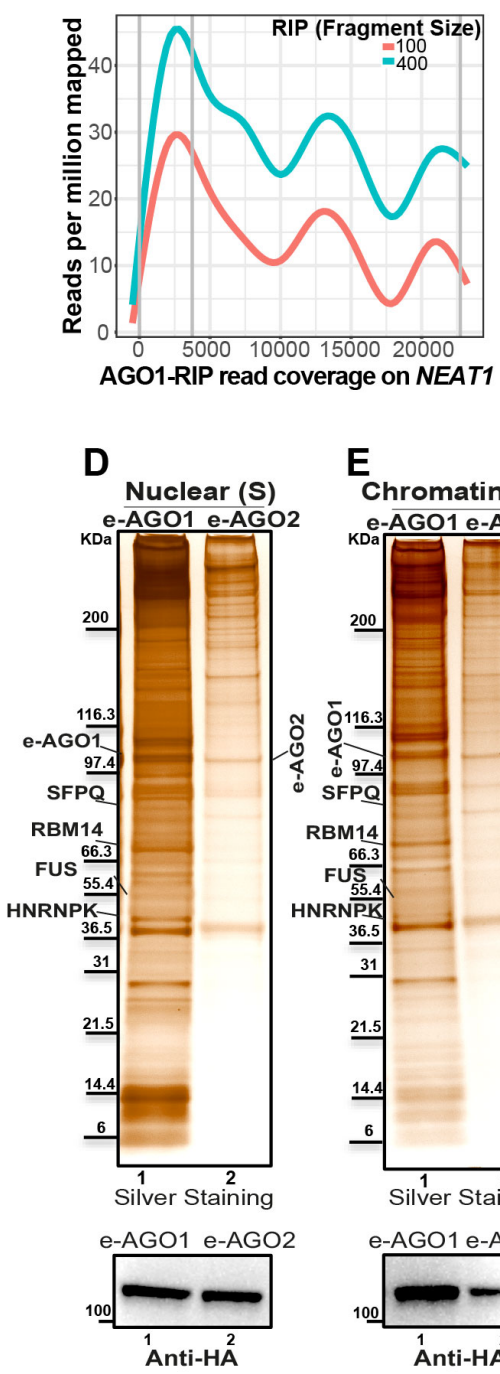

E
B

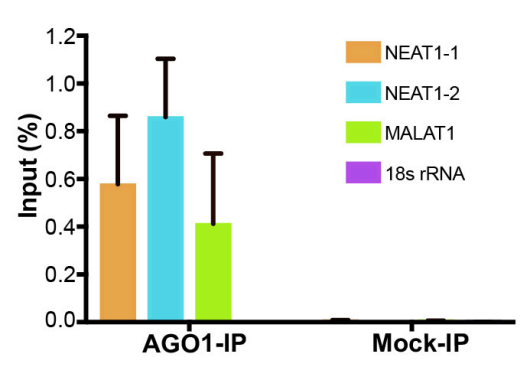
2 Chromatin (CB)

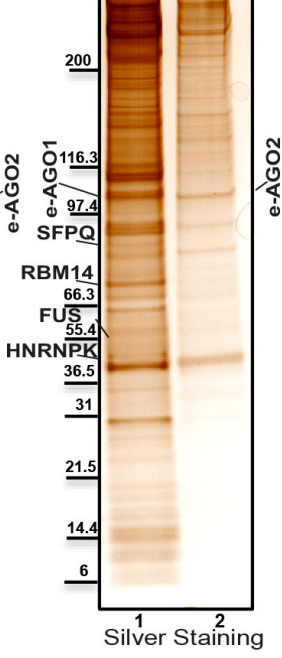
e-AGO1 e-AGO2

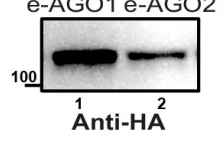

NEAT 1

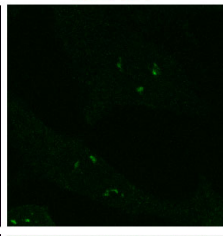

C

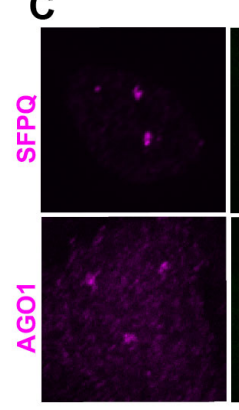

NEAT1
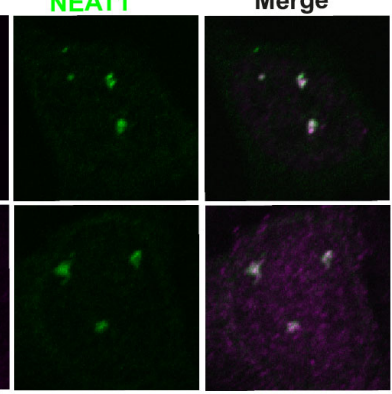

G

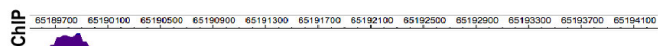
엉

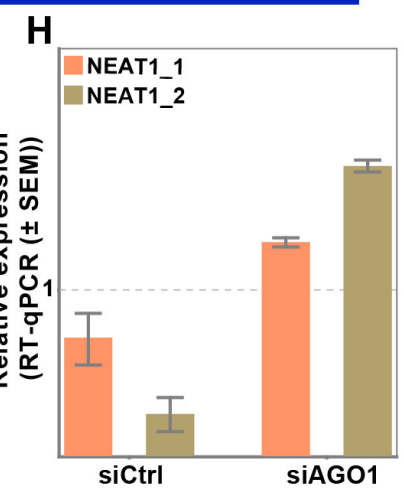

Merge
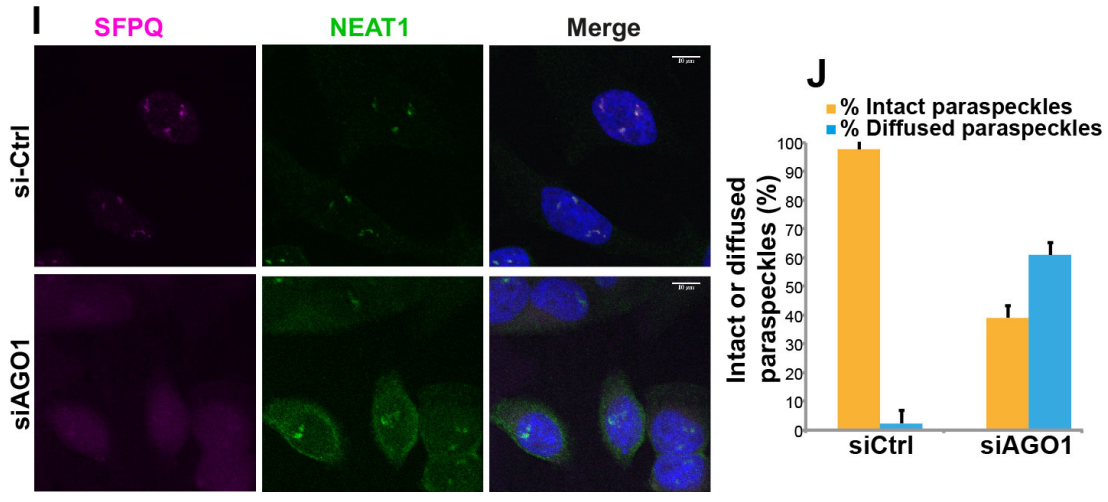
bioRxiv preprint doi: https://doi org/10.1101/525527; this version posted January 20,2019 . The copyright holder for this preprint (which was not certified by peer review) is the author/funder, who has granted bioRxiv a license to display the preprint in perpetuity. It is made available under aCC-BY-NC 4.0 International license.

\section{Shuaib_Fig4}

A

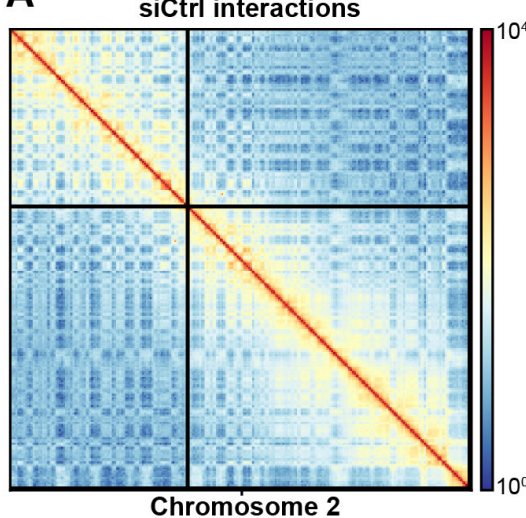

D

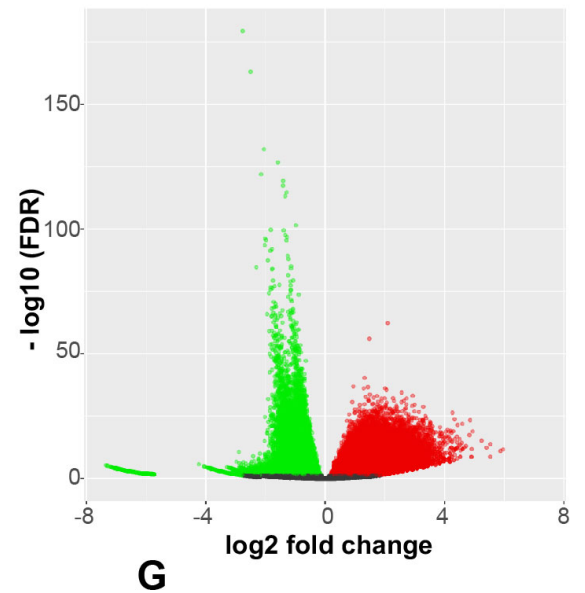

B

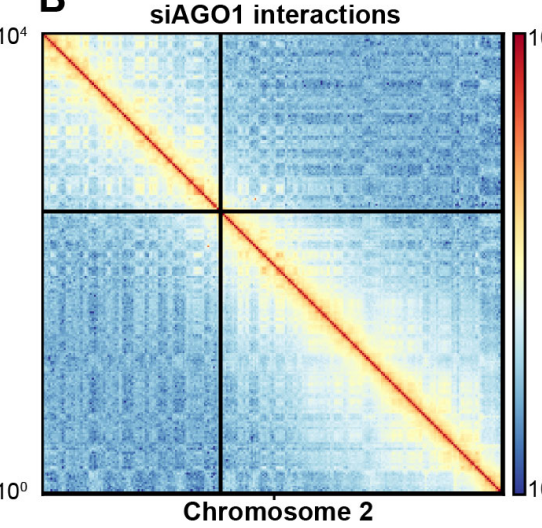

E

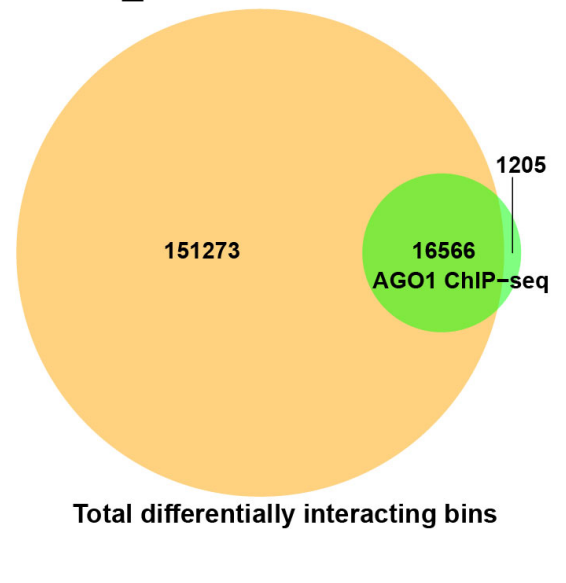

C siAGO1 versus sictrl

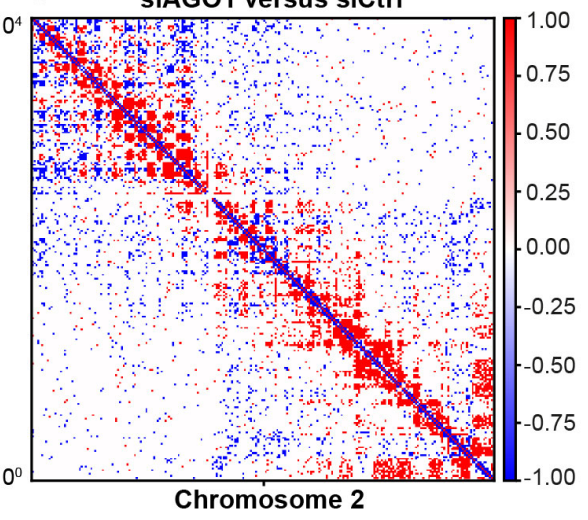

$\mathbf{F}$

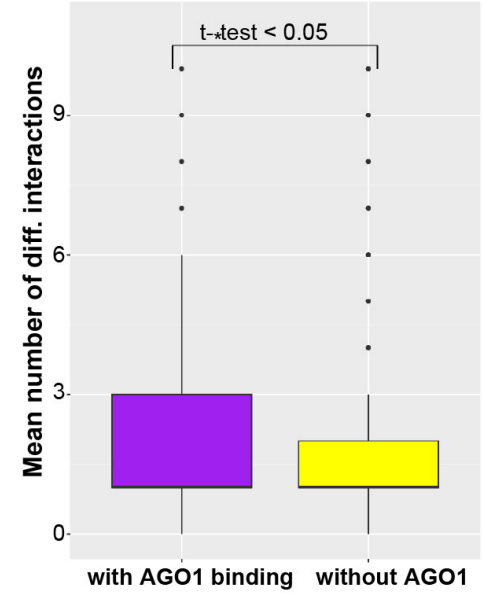

Chr1: 12166178-117438294

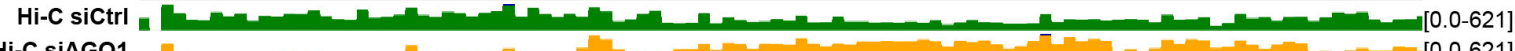

Hi-C siAGO1

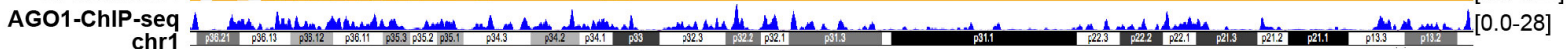

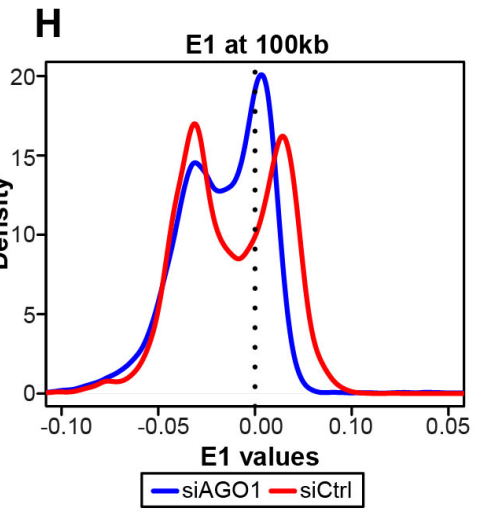

\section{I}

Genome-wide compartment switching

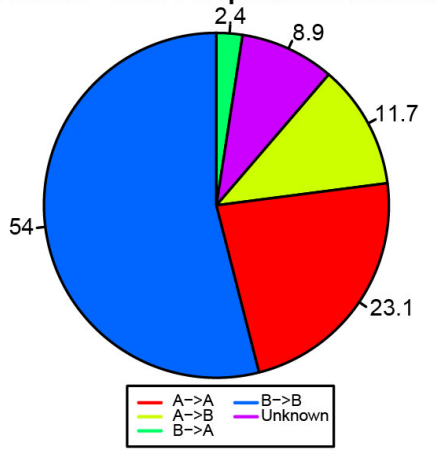

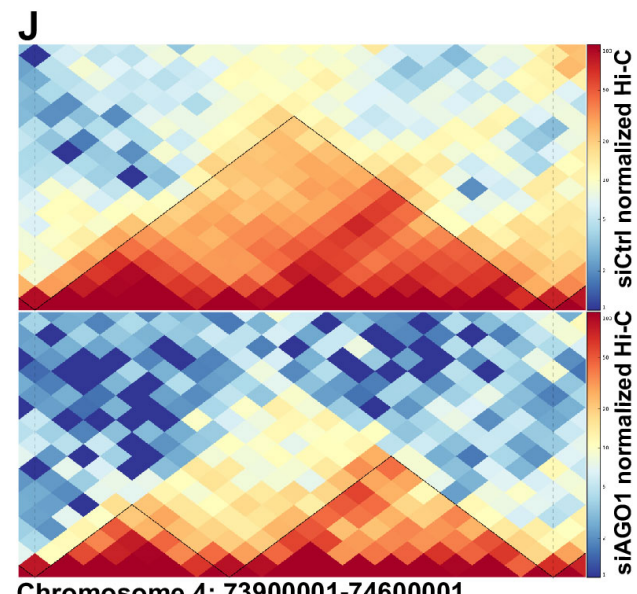


bioRxiv preprint doi: https://doi.org/10.1101/525527; this version posted January 20, 2019. The copyright holder for this preprint (which was not certified by peer review) is the author/funder, who has granted bioRxiv a license to display the preprint in perpetuity. It is made available under aCC-BY-NC 4.0 International license.

\section{Shuaib_Fig5}

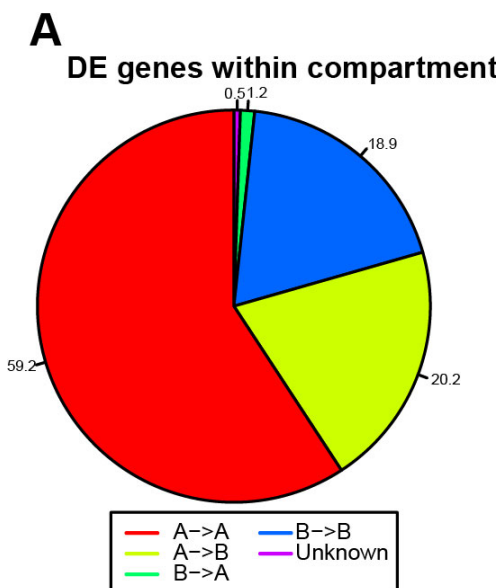

D

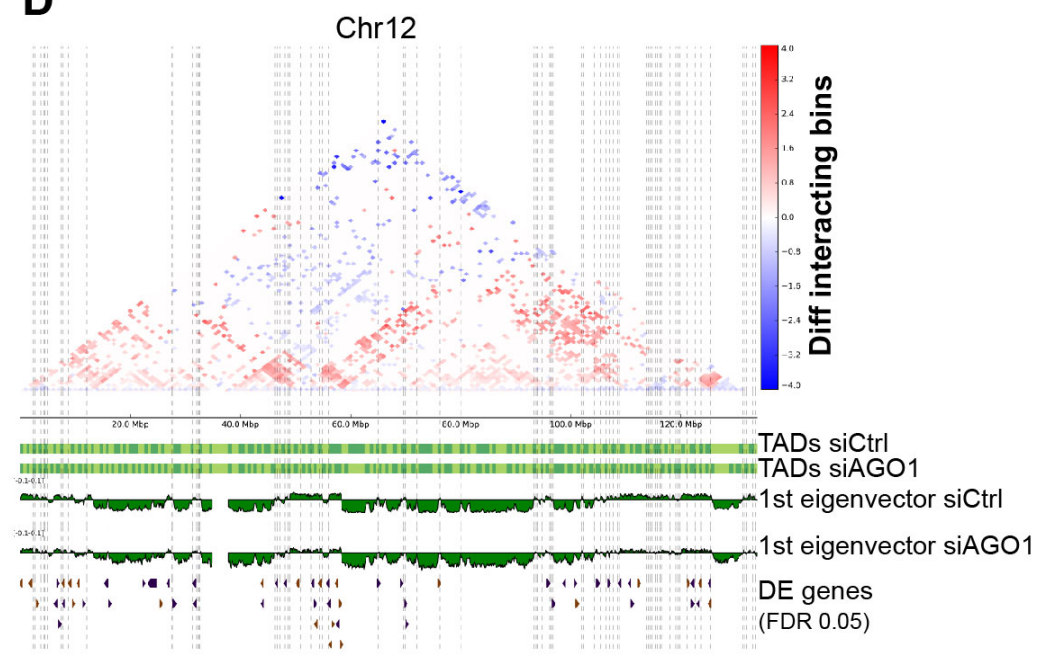

B

C
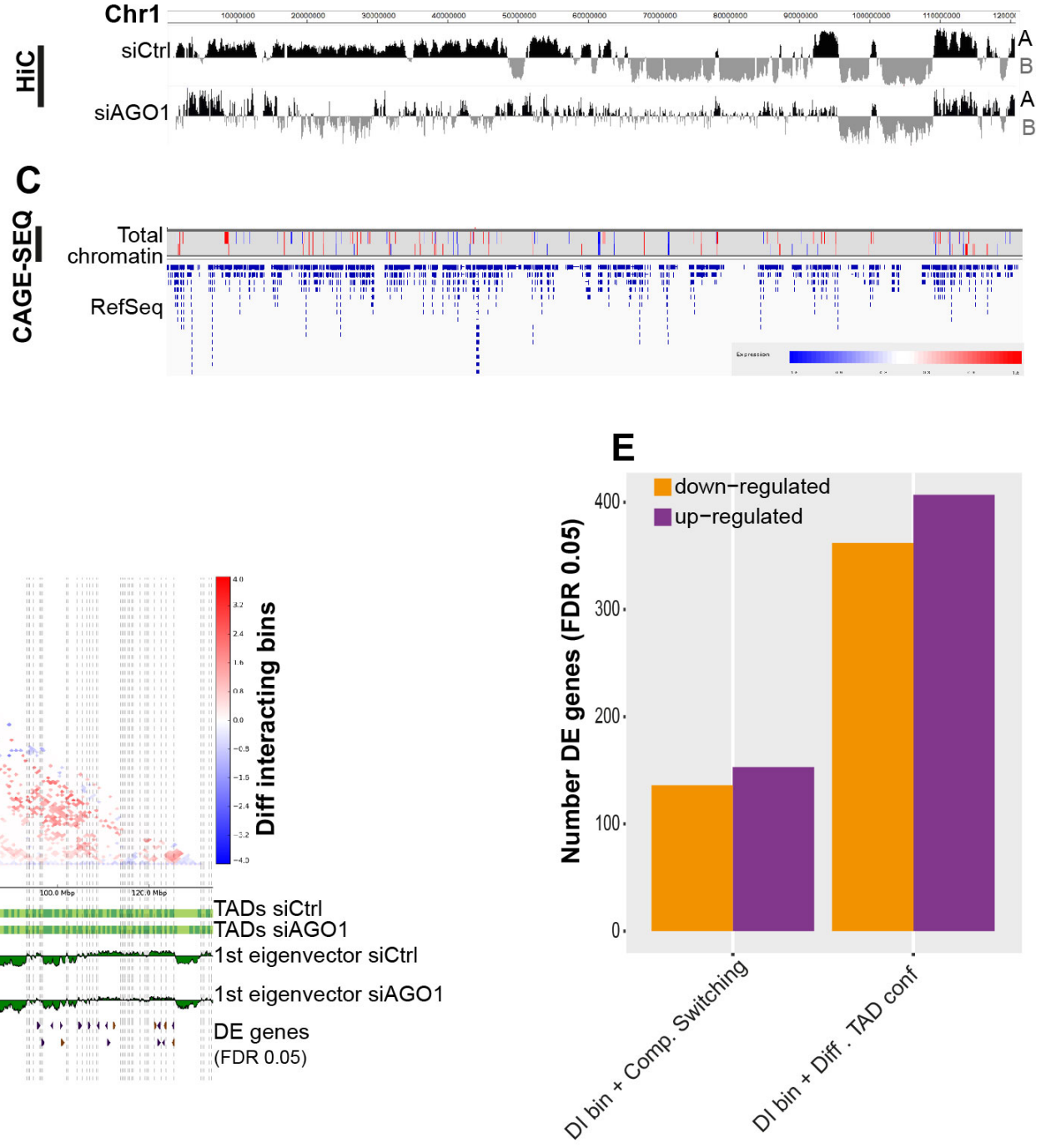
bioRxiv preprint doi: https://doi org/10.1101/525527; this version posted January 20,2019 . The copyright holder for this preprint (which was not certified by peer review) is the author/funder, who has granted bioRxiv a license to display the preprint in perpetuity. It is made available under aCC-BY-NC 4.0 International license.

\section{Shuaib_Fig6}

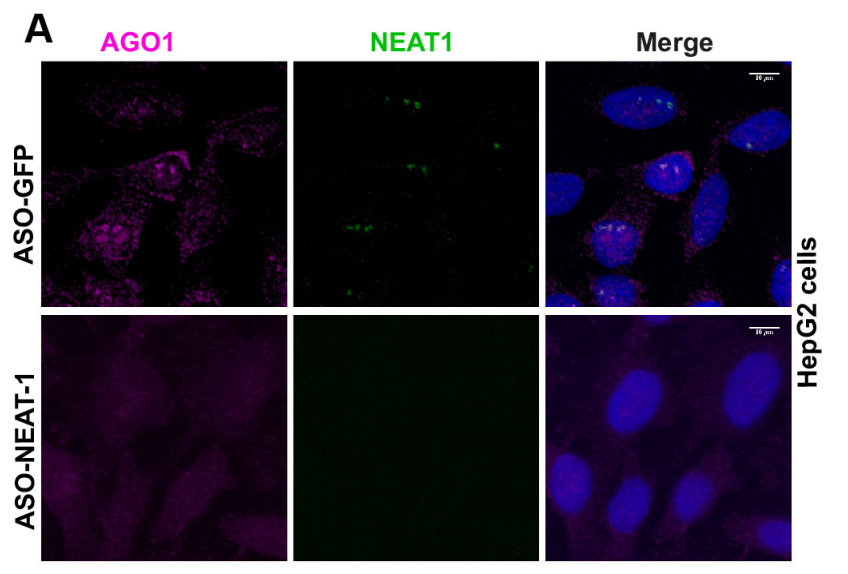

B
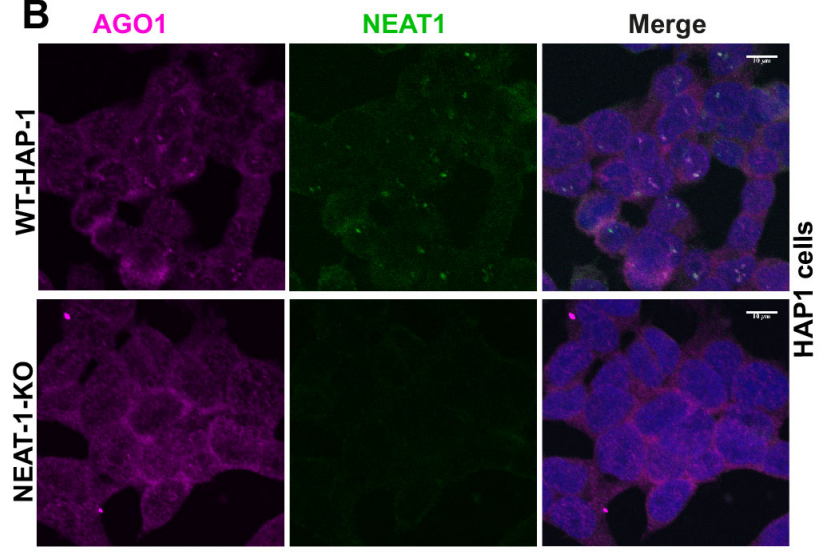

C AG01 ChIP-seq

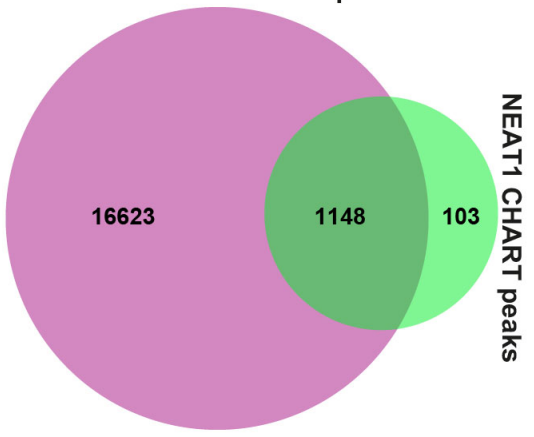

E

WT HAP1: chr21

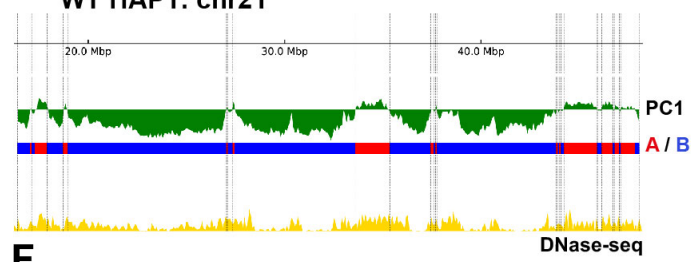

G

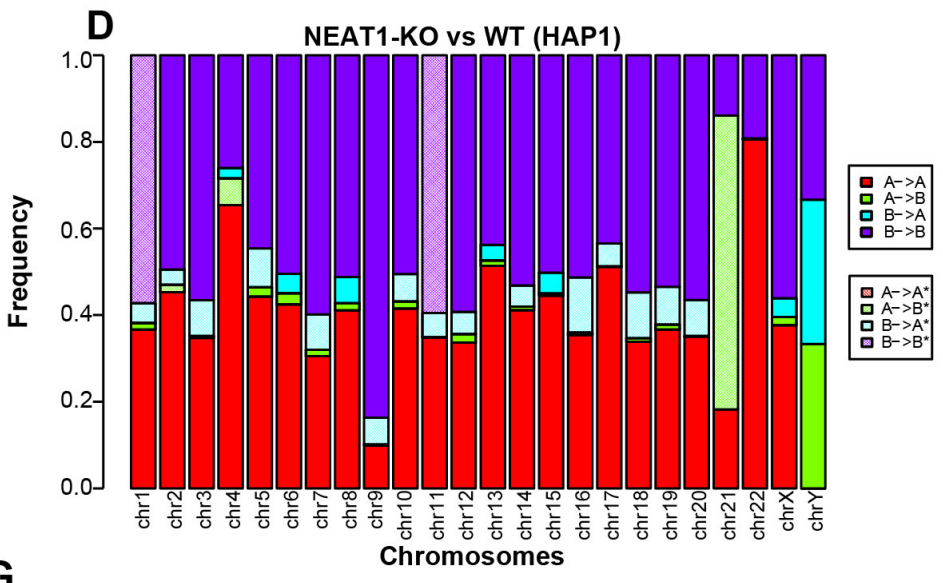

Chromosome 16

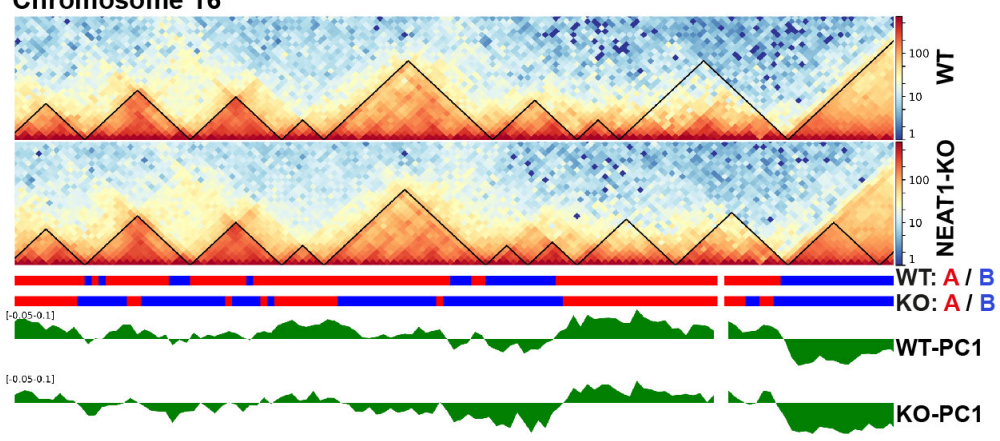

DNase-seq 
bioRxiv preprint doi: https://doi.org/10.1101/525527 this version posted January 20,2019 . The copyright holder for this preprint (which was not certified by peer review) is the author/funder, who has granted bioRxiv a license to display the preprint in perpetuity. It is made available under aCC-BY-NC 4.0 International license.

\section{Shuaib_Fig7}

\section{A}
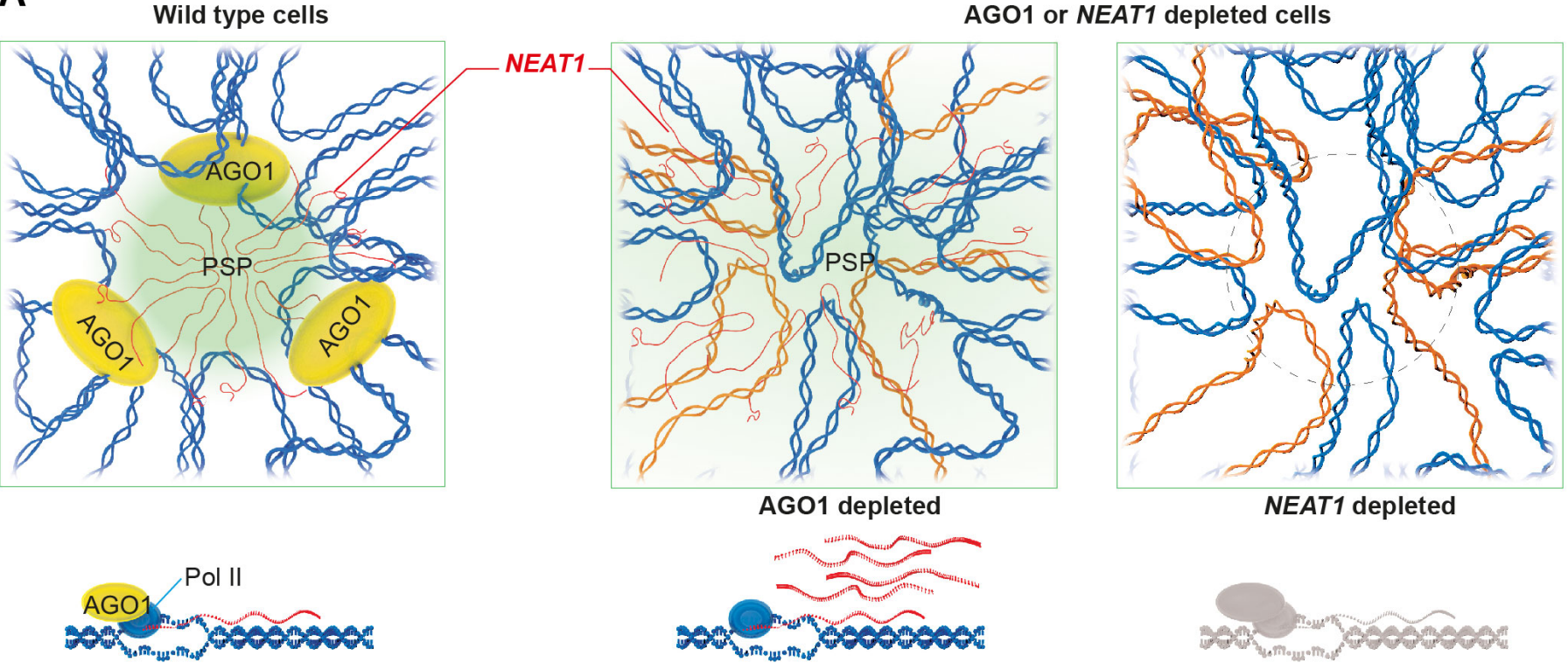